BANCA D'ITALIA

E U R O S I S T E M A

Questioni di Economia e Finanza

(Occasional Papers)

Market shares in manufacturing value-added: is the picture different?

by Alberto Felettigh and Giacomo Oddo 

13 BANCA D'ITALIA

E U ROS IS T E MA

\section{Questioni di Economia e Finanza}

(Occasional papers)

Market shares in manufacturing value-added:

is the picture different?

by Alberto Felettigh and Giacomo Oddo

Number 336 - July 2016 
The series Occasional Papers presents studies and documents on issues pertaining to the institutional tasks of the Bank of Italy and the Eurosystem. The Occasional Papers appear alongside the Working Papers series which are specifically aimed at providing original contributions to economic research.

The Occasional Papers include studies conducted within the Bank of Italy, sometimes in cooperation with the Eurosystem or other institutions. The views expressed in the studies are those of the authors and do not involve the responsibility of the institutions to which they belong.

The series is available online at www.bancaditalia.it .

ISSN $1972-6627$ (print)

ISSN 1972-6643 (online)

Printed by the Printing and Publishing Division of the Bank of Italy 


\title{
MARKET SHARES IN MANUFACTURING VALUE-ADDED: IS THE PICTURE DIFFERENT?
}

\author{
by Alberto Felettigh* and Giacomo Oddo*
}

\begin{abstract}
Using an extension of the methodology proposed by Koopman, Wang and Wei (2014) for quantifying the domestic value added in a country's exports of manufactures, this paper provides calculations of the market shares in value-added for a number of countries and compares them with the standard shares in global gross exports. The data show different levels and dynamics between advanced and developing countries, with 2004 apparently marking a watershed. Focusing on the four main euro-area countries, the paper offers a sectoral interpretation for the falling intensity of the domestic value added in exports.
\end{abstract}

JEL Classification: F12, F14, F15.

Keywords: market shares, value added exports, global value chains, competitiveness.

\section{Contents}

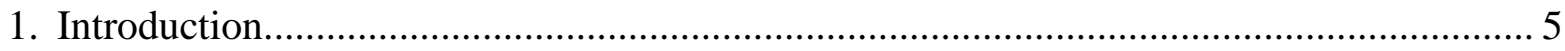

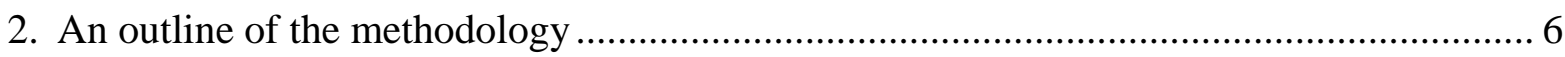

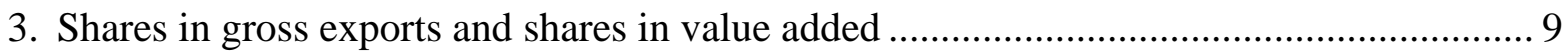

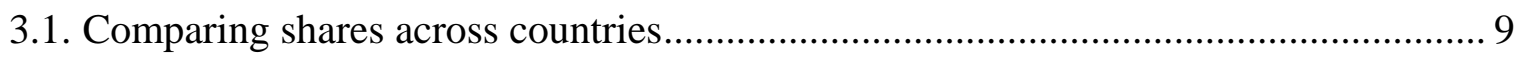

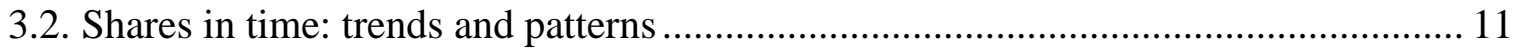

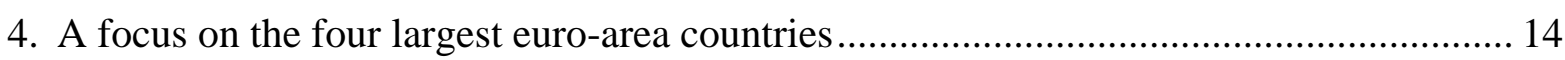

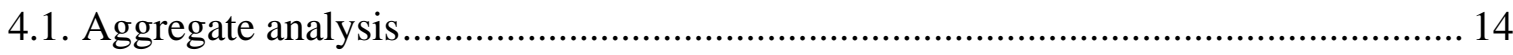

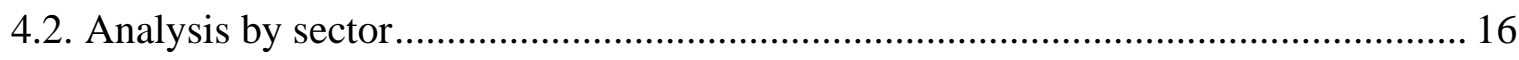

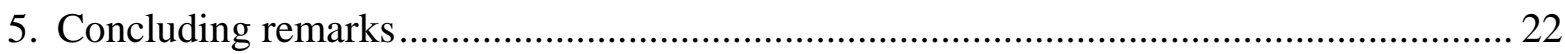

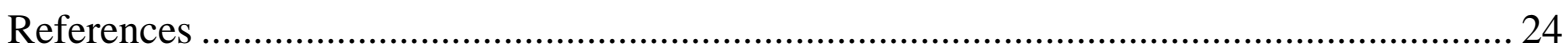

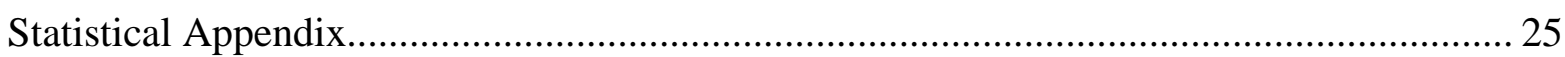

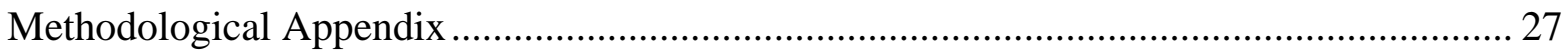

* Bank of Italy, DG Economics, Statistics and Research. 



\section{Introduction ${ }^{1}$}

The market share in world exports is often used to synthetically assess a country's trade performance and competitive stance. It has ascended to a normative status within the European debate since the European Commission included it in the Scoreboard for the Macroeconomic Imbalance Procedure. However, it is an indicator notoriously unable to grasp all multiple dimensions of competitiveness (Krugman 1994, 1996).

One of the major flaws of shares in world exports is that they are not in a direct and stable relation with GDP growth. The main conceptual reason is that trade statistics record revenues from exporting activity, not value added, and that the ratio between these two magnitudes evolves with the diffusion of global value chains (GVCs). International fragmentation of production and the growing exchanges of intermediate goods have made indicators based on gross exports alone (that is, without the simultaneous analysis of imports) less and less informative on the effective contribution of exports to GDP. In this paper, we set off to look at market shares shifting the focus from gross exports to their domestic-value-added content.

Gross exports can be decomposed into three main components: domestic value added, foreign value added and a residual double-counting term. The first component reflects the use of domestic inputs in producing exports and thus captures the contribution of gross exports to GDP (we label it GDP in exports or GDPX in short ${ }^{2}$ ). The second component reflects the use of foreign inputs in producing exports; it is a refinement of the concept of "import content of exports", which does not control for the fact that a country's imports may in fact contain a (small) contribution of domestic inputs. Lastly, the double-counting component arises from intermediates that cross the national border back and forth as they get processed in successive stages of production and thus get recorded multiple times in aggregate and bilateral trade statistics.

Relying on the World Input Output Database and on the tools developed by Cappariello and Felettigh (2015), this paper investigates to what extent countries' share in world merchandise (gross) exports differs from its value-added-exports counterpart (that is the share in world GDPX), both in levels and in dynamics, for the period 1995-2011.

Our estimates imply a number of measurement assumptions that are sketched in the next section. Our main conclusion is that in general there is an overall consistency both in terms of levels and medium-term dynamics between the market share based on gross exports and the market share based on value added, especially for developed economies.

Yet, there are differences: from 1995 up until the eve of the Great Trade Collapse in 2009, the Italian market share recorded a cumulative drop, relative to Germany, by around 15 percentage points in gross-exports terms, but by less than 10 points in value-added terms. Differences arise also for other large euro-area economies: while levels and dynamics are similar for either notion of market share in each of the main four countries, the performance of Germany is generally less outstanding, relative to France and especially Italy, when looked at in value-added terms.

The "mismatch" between the two metrics tends to decrease over time for all large advanced exporters, whereas it is increasing for China and some emerging economies. A common narrative interpretation of emerging economies' involvement in GVCs holds that these countries have been moving away from the central through of the "smile curve" 3 (low-value-added manufacture and

\footnotetext{
${ }^{1}$ While retaining full responsibility for any errors and omissions, the authors wish to thank Andrea Brandolini, Rita Cappariello, Silvia Fabiani, Roberto Tedeschi (Bank of Italy) and Frauke Skudelny (European Central Bank) for useful comments and suggestions on earlier drafts of this paper. The views expressed here are solely those of the authors and do not necessarily reflect the opinions of the Bank of Italy.

${ }^{2}$ The terminology is borrowed from Cappariello and Felettigh (2015).

${ }^{3}$ ACER Computer's CEO Stan Shih was the first one to put forth the idea that GVCs develop along a U-shaped curve (that is, a smile) where the centre of value creation in the manufacture or assembly of product is flanked on either side by higher-value-added services activities (concept development, design, engineering, R\&D on the pre-manufacturing
} 
assembly) towards pre- and post-manufacturing high-value-added services activities. We find some evidence supporting this interpretation: the growth of emerging economies as surmised from market shares was stronger in gross-exports terms than in value-added terms until 2004, while the opposite held afterwards. Commodity prices may however have played a role towards such trend reversion (the steep increase in oil prices started around 2004 and natural resources are concentrated in developing countries).

The ability of aggregate gross exports to activate domestic value added is a key driver of the relation between a country's market share in gross exports and its share in world GDPX. In our focus on the four largest euro-area economies we offer a sectoral analysis of such pivotal variable. We document that the fall in the ability of aggregate gross exports to activate domestic value added is largely due to the fact that increasing participation in GVCs is widespread across sectors. Secondly, we find some evidence that that the diffusion of GVCs - and the ensuing improvements in competitiveness due to outsourcing of intermediates inputs from abroad at cheaper prices (or of better quality) - seems to impose a trade-off between favorable export market shares dynamics and the ability of exports in contributing to GDP growth.

This is a weakening of the correlation, if not the causal link, between "external competitiveness" developments and GDP growth. Indeed, identical dynamics of "external competitiveness" are compatible with different developments of exports' ability to spur domestic growth, ${ }^{4}$ and it is even possible for improvements in competitiveness to occur solely to the benefit of foreign value added. ${ }^{5}$ While monitoring shares in world GDPX helps better understanding the economic phenomena at play, the question ultimately arises of whether an excessive emphasis is being put on the evolution of export market shares when assessing "external competitiveness".

The paper is organized as follows: Section 2 outlines the methodology we implement in Section3, which considers the forty countries included in the WIOD dataset and offers an overview on market shares in gross exports and in value added, comparing them across countries and across time. Section 4 narrows the focus to the four main euro-area countries and widens the analysis by deepening into the sectoral dimension. A final section draws conclusions.

\section{An outline of the methodology}

After the pioneering work of Hummels et al. (2001), the biggest leap forward towards a deeper understanding of GVCs has probably been made with the estimation of Inter-Country Input-Output (ICIO) tables, and in particular with the publication of the TiVA database by the OECD and of the World Input Output Database (WIOD) by Timmer (2012). WIOD tables match national IO (supply and use) tables, breaking down the foreign sector among the various partner countries, both on the export (use) and on the import (supply) side. This new ground-breaking empirical basis has opened up a new stream of analysis, mainly aimed at decomposing the domestic value added embodied in exports into "source" countries and sectors and "user" countries and sectors.

While Johnson and Noguera (2012) is the seminal contribution of this "trade in value added" strand of research, a fully coherent analytical (and algebraic) framework was only developed by Koopman,

side; logistics, sales, marketing, branding, after-sale services on the post-production side). See for instance Baldwin (2012) for an academic presentation of the smile curve.

${ }^{4}$ This has distributional consequences (among the domestic factors of production and between domestic and foreign inputs) that this paper does not pursue.

${ }^{5}$ Abstractly, imagine an exporter that profitably decides to offshore some of its activity in order to simultaneously serve part of its foreign markets and produce, at a cheaper price, intermediate inputs for the downsized domestic plant. The domestic labor content of foregone (domestic) exports could indeed be in excess of the extra profits cashed in by the entrepreneur (both at home and abroad), despite the improved competitiveness of surviving domestic exports (thanks to the outsourcing of intermediates). 
Wang and Wei (2014, KWW henceforth), who offered a methodological approach for decomposing gross exports into various details of three main components: domestic value added, foreign value added and a double-counting term.

Focusing on the first component, the domestic value added embodied in exports (GDPX) tends to grow less than gross exports (GX) when trade in intermediate goods and the complexity of GVCs increase. We will refer to the ratio between GDPX and GX as "GDPX-intensity", since it represents the amount of GDP that is embodied in one unit (one dollar-worth) of exports.

Cappariello and Felettigh (2015) integrate the KWW framework by introducing an additional dimension: the domestic sector where the value added embodied in exports originated, in order to keep track of the domestic value added exported by one sector (manufacturing, for instance) but created in a different sector (services, for example). With this KWW-enhanced framework, Cappariello and Felettigh calculate GDPX for each of the forty countries included in the WIOD database, broken down by exporting-sector and by origin-sector.

Their approach is especially useful for the purposes of this paper as we need to restrict goods trade, since we rely on WIOD tables in USD dollars at current prices and exchange rates (available years are 1995 to 2011). Ideally, one would like to exclude commodities and raw materials: these sectors are characterised by wide price fluctuations, which make it almost impossible to distinguish changes in value added due to actual GVC developments from changes in value added due to price fluctuations alone (terms-of-trade effects). ${ }^{6}$ To clarify, when all goods and services are considered a surge in oil prices tends to mechanically decrease the GDPX-intensity of oil-importing countries, as the foreign value added embodied in exports increases, independently of any development in GVCs or the way production is organized. Vice-versa, spikes in oil prices tend to benefit both exports and the GDPX of countries rich in natural resources. In summary, inflation in raw materials tends to increase both shares in world exports and in world GDPX for countries rich in natural resources, and vice-versa for the remaining countries. This is one of the reasons why looking at a country's market share can be misleading unless the analysis is conducted in comparative terms, relative to similar competitors, and covers a sufficiently long time span.

In order to address measurement issues related to commodity prices, we choose to focus on exports of manufacturing goods and on their domestic value added content, irrespective of the sector where it originated. That is, we exclude raw materials entirely from exports but only partially from GDPX, since we still consider the domestic value added that is embodied in manufacturing exports while originating in the (domestic) mining and quarrying sector. Excluding also the latter component is part of our future research agenda.

We claimed earlier that the ability of aggregate gross exports to activate domestic value added (the GDPX-intensity) is a key driver of the relation between a country's market share in gross exports (GX-share hereafter, denoted as $s_{i}$ ) and its share in world GDPX (GDPX-share hereafter, denoted as $\sigma_{i}$ ). More precisely, if the GDPX-share of a given country $i$ is larger (smaller) than its GX-share, then its GDPX-intensity $\gamma_{i}$ is higher (lower) than the global average GDPX-intensity $\gamma_{w}$ (and viceversa). In formulas, if we define (a subscript $w$ indicating variables for the world aggregate)

$$
\gamma_{i} \equiv \frac{G D P X_{i}}{G X_{i}}, \quad s_{i} \equiv \frac{G X_{i}}{G X_{w}} \text { and } \sigma_{i} \equiv \frac{G D P X_{i}}{G D P X_{w}},
$$

then it can be algebraically verified that:

$$
\sigma_{i}>s_{i} \Leftrightarrow \gamma_{i}>\gamma_{w}
$$

The following identity also holds:

\footnotetext{
${ }^{6}$ Cappariello and Felettigh (2015) experiment with a preliminary and incomplete assessment.
} 


$$
\frac{\sigma_{i}}{s_{i}}=\frac{\gamma_{i}}{\gamma_{w}}
$$

Equation 2 implies that looking at countries' relative position with respect to the global average GDPX-intensity is a shorthand way of looking at the difference ${ }^{7}$ between countries' own shares $\sigma_{i}$ and $s_{i}$. We will often use this representation (relative position in GDPX-intensity) for comparing shares $s$ and $\sigma$ throughout the paper.

Notice in particular from equation (3) that simply comparing $s_{i}$ and $\sigma_{i}$ is not sufficient for determining country $i$ 's GDPX-intensity, since GX-shares and GDPX-shares differ in the denominator: world gross exports are larger than world GDPX since the same holds at the individual country level (due to the foreign-value-added and the double-counting components of gross exports).

We conclude this section with two caveats about our analysis, which rests on the assumption that GDPX-intensities can be accurately measured from the WIOD database. In fact, this may be a poor postulate, especially for countries that engage heavily in "processing trade", 8 as documented in the literature. According to Dean, Fung and Wang (2011), from 1995 to 2007 over 50\% of Chinese exports were classified as processing exports; they split the official Chinese IO tables into normal and processing imports of intermediate goods to find that the domestic value added of normal exports in 1997 and in 2002 was respectively around five-fold and three-fold that of processing exports. Chen et al. (2012) build an IO table for China containing separate technical coefficients for processing exports and normal exports, also finding that domestic value added is much lower in the first case. Koopman, Wang and Wei (2014) calculate on their ICIO table that the domestic value added content of processing exports from China and Mexico in 2004 was around 40\%, which is roughly half the value registered in normal exports. Ahmad et al. (2012) use Turkish firm-level data to estimate technical coefficients for firms by distinguishing their primary market between domestic and foreign; they find that the share of foreign content in Turkish exports in 2005 was higher than estimates based on data that do not distinguish between main outlet markets.

In summary, the literature pointed out that properly considering foreign value added absorbed via processing trade would lead to downsized GDPX-intensities for some emerging countries. In order to sense how much such a correction can affect also world aggregates, we have experimented with using adjusted GDPX-intensities for China and Mexico, as estimated by Koopman, Wang and Wei, and correcting world GDPX accordingly: the GDPX-shares of the two countries are indeed reduced, with no significant change, however, for the other main exporters in the world (see the Methodological Appendix). No definite conclusion is however warranted, since a thorough assessment would require correcting estimates for all the countries in the dataset (including advanced economies). Still, we would expect some rebalancing in favour of advanced countries to occur if global IO tables were improved to distinguish between processing and "normal" trade or between relevant enterprise characteristics (the OECD has ongoing projects in this direction).

Finally, a second measurement issue worth recalling is that our definition of GDPX includes the domestic value added embodied in exports of manufactures while originating in the (domestic) mining and quarrying sector, which leads to an overestimation of GDPX-shares for countries rich in natural resources.

\footnotetext{
${ }^{7}$ More precisely, the ratio, as equation (3) shows.

${ }^{8}$ That is exports of goods processed in the country using intermediates that were imported under the strict condition of being used only in export-oriented production.
} 


\section{Shares in gross exports and shares in value added}

\subsection{Comparing shares across countries}

Figure 1 shows, for each country in the WIOD database, its average share in world gross exports, its average share in world GDPX and the percentage difference between the two, which shows the impact of moving to the GDPX metric better than the absolute difference for small economies. Averages are taken over the available period (1995-2011) and countries are ordered according to their GX-share. ${ }^{9}$

Looking at global market shares "through the lenses of value added" does not seem to convey a radical different ranking of world economies from what can be surmised from nominal export data. We can observe some empirical regularities:

1. A cluster of "big exporters" with both shares above $4 \%$ emerges: ${ }^{10}$ Germany, the US, China, Japan, France, Italy, Great Britain (disregarding the residual area "Rest of the World"). ${ }^{11}$ Each country in this group has a share in value added that is larger than the share in gross exports by less than 10 per cent, except for Japan and the US;

2. in remaining countries, the GX-share tends to be larger than the corresponding GDPX-share; the exceptions include economies that are relatively rich in natural resources (Brazil, Indonesia and especially Russia).

Figure 1. Market shares in gross exports and market shares in value added (1) (percentage points)

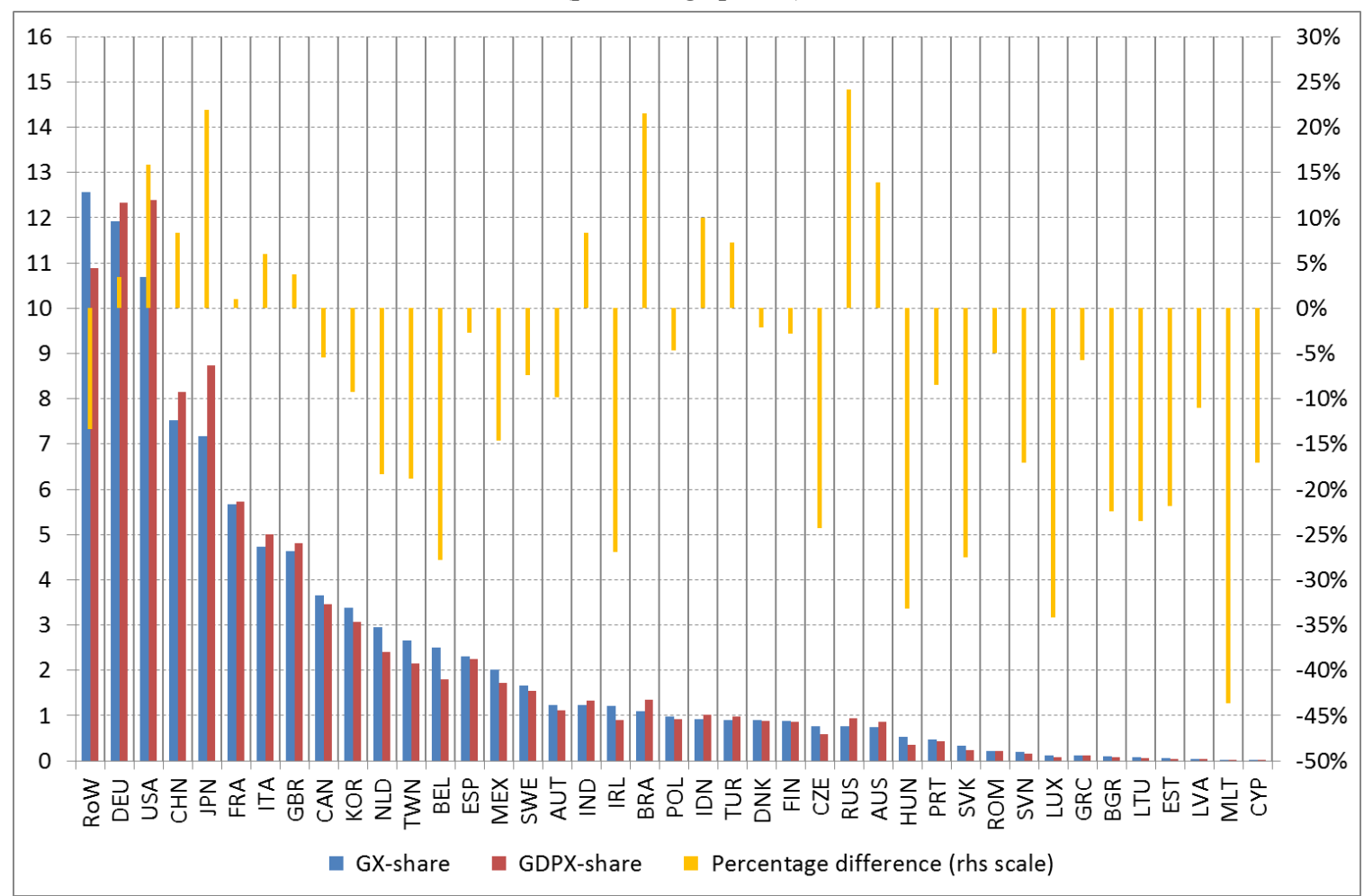

Source: authors' calculations on WIOD data.

(1) Average shares in 1995-2011. Countries are ordered in terms of decreasing GX-share. The percentage difference is between countries' GDPX-share and GX-share. Only exports of manufactures are considered.

\footnotetext{
${ }^{9}$ Figures A1 and A2 in the Appendix replicate Figure 1 for the initial (1995-96) and the final biennium (2010-11).

${ }^{10}$ The same cluster emerges using data on exports of manufactures by the WTO, with very similar shares. The corresponding shares in overall merchandise exports (thus including oil and other commodities) are lower.

${ }^{11}$ In WIOD tables it is defined as the difference between world aggregates and the sum of the forty countries in the database.
} 
Figure 2 exploits equation (2) above for re-casting Figure 1 in terms of GDPX-intensities: for countries on the left of the "world" shaded bar (namely, for countries with a GDPX-intensity higher than $72 \%$ ), the share in value added is larger than the share in gross exports.

GDPX-intensity varies a lot across countries, ranging from $88 \%$ for Russia and Japan down to $41 \%$ for Malta. At the very top of the ranking (intensities above $75 \%$ in the 1995-2011 average) we find the BRICs group, Japan, the US, Australia, Indonesia, Turkey and Italy. High GDPX-intensities are due either to limited participation in GVCs or to specialization in the value-added intensive stages of the smile curve, so that the amount of imported foreign value added is relatively small, or to the availability of raw materials and natural resources, as already mentioned. As it might be expected a priori, advanced countries (as approximated by the set of OECD members within WIOD countries, yellow bar in the figure) display a higher-than-average GDPX-intensity; we will come back to this issue when addressing dynamics.

Italy and Germany stand out as the European countries with the highest GDPX-intensity, 3.3 and 1.5 percentage points above the OECD average, respectively. GDPX-intensities around or below $60 \%$ are found for emerging (Mexico, Taiwan) and many Eastern European countries, which are often suppliers of intermediates to more advanced economies; low GDPX-intensities are also registered in small open economies or countries with a comparative advantage in services and a less relevant manufacturing sector (often the two sets overlap, as in the case of Luxembourg or Ireland).

The average GDPX-intensity in the period 1995-2011 for the world economy was about $72 \%$; it shrank from $77 \%$ in $1995-96$ to just below $69 \%$ in $2010-11$, reflecting the diffusion of GVCs and the ensuing increase in intermediates trade. The fall was a common feature for all countries except Russia, Canada, Cyprus, Estonia and Malta. The next section addresses dynamics more in detail.

Figure 2. GDPX-intensity by country (1) (percentage points)

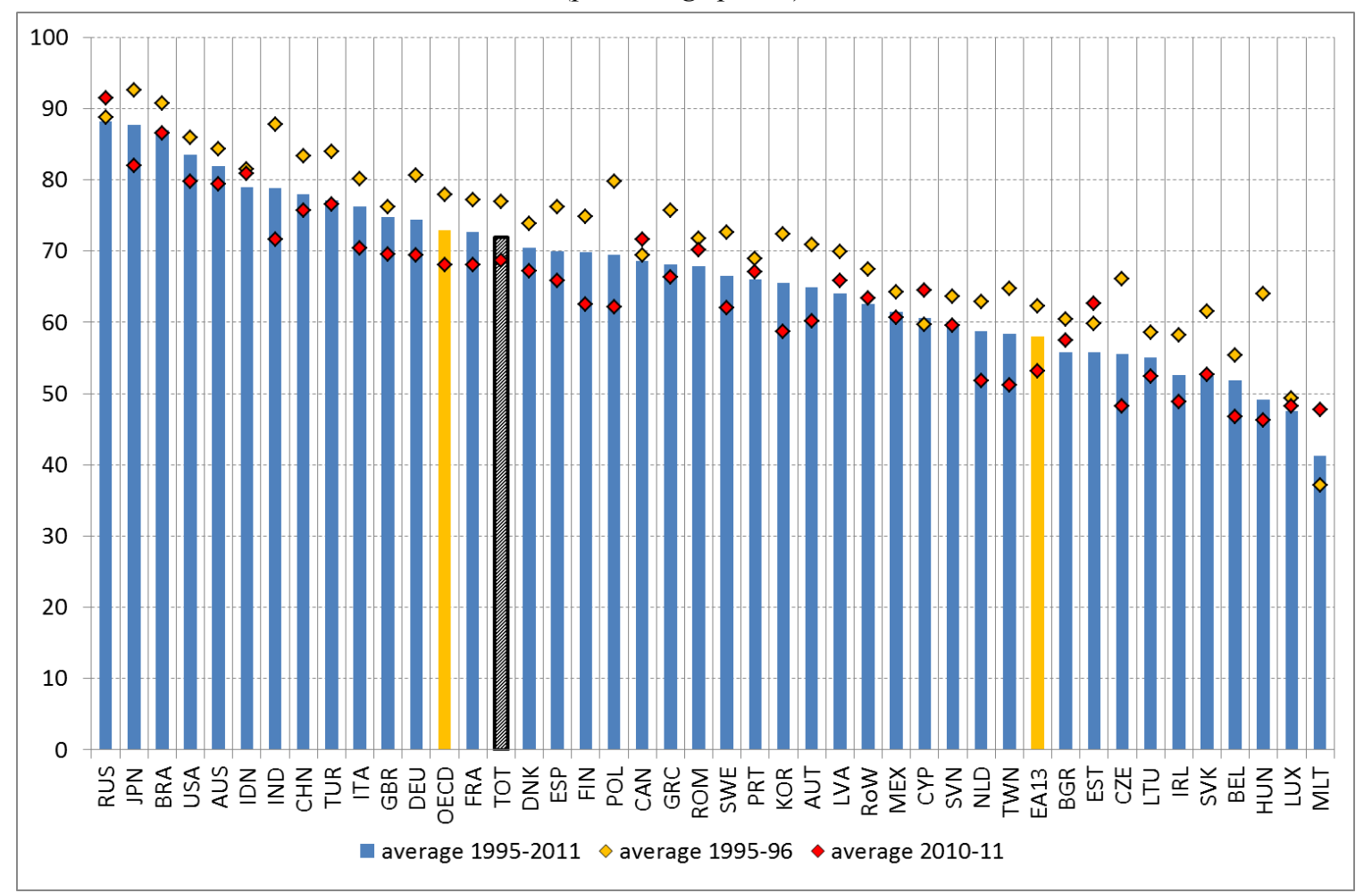

Source: authors' calculation on WIOD data.

(1) Yellow bars indicate the areas we derived by aggregating individual countries. The shaded bar represents the global average. Countries are ordered in terms of decreasing GDPX-intensity. Only exports of manufactures are considered.

Notes: RoW is the residual area "Rest of the world"; EA13 is the euro area (with 17 members) less France, Germany, Italy and Spain. 


\subsection{Shares in time: trends and patterns}

Figure 3 compares the variations that the two shares registered in each country between the beginning and the end of the period under examination. As also found by Benkovskis and Wörz (2015), for a vast majority of countries both market shares exhibit very similar dynamics ${ }^{12}$; in particular, both shares lead to the same partition between "gainers" (left panel of Figure 3) and "losers" (right panel), the only exception being Spain. China stands out for the very large increase in both dimensions: Chinese shares surged from 3.7 to $15.2 \%$ in value-added terms and from 3.4 to $13.8 \%$ in gross-exports terms, a result that mirrors a fall in GDPX-intensity in line with the world average.

Figure 4 reports how, for each country, the difference (s- $\sigma$ ) between the two shares evolved through time, comparing the mismatch at the beginning with that at the end of the period under consideration. As another sign of convergence in the information conveyed by the two metrics, for a large number of advanced countries (which are also large exporters) the difference between the two shares, in absolute value, either shrank markedly or remained virtually steady. Germany and Japan are two remarkable examples; Italy also registered a reduction of its (modest) difference between the two shares. The US, France, the UK and the Netherlands had their respective gaps confirmed.

\section{Figure 3. Percentage changes between biennia 1995-96 and 2010-11 in gross-exports market shares and in value-added market shares (1)}

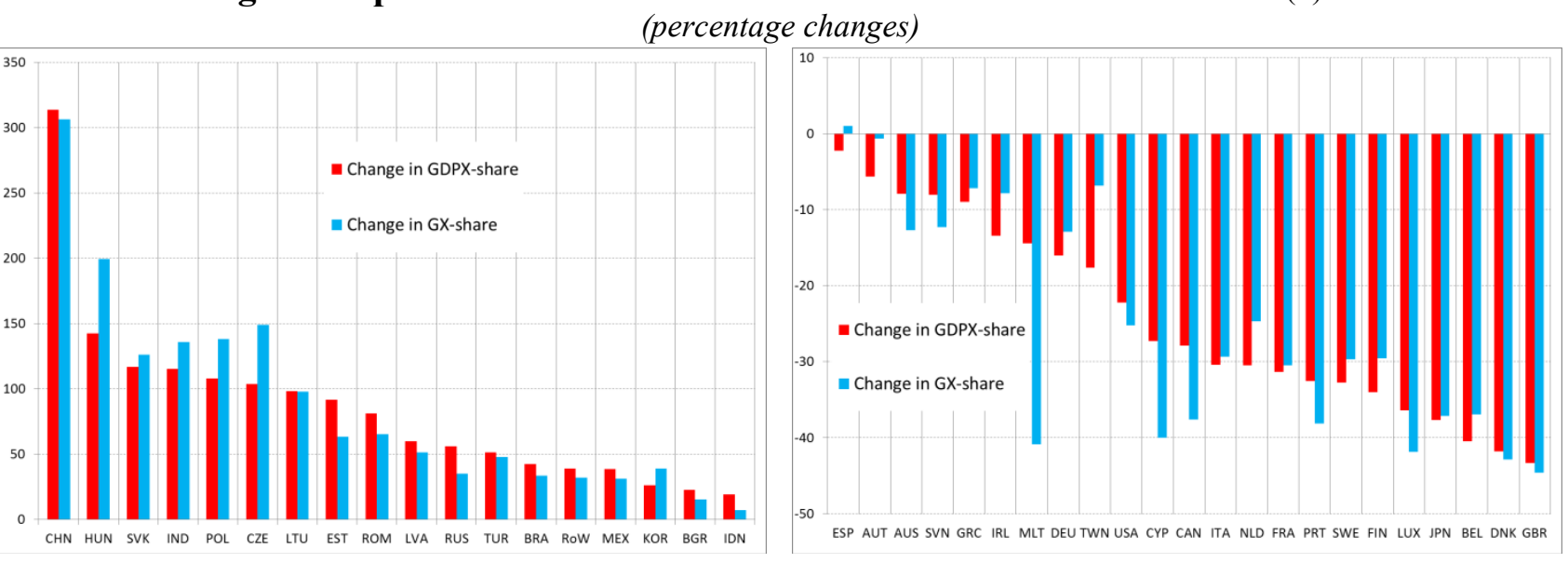

Source: authors' calculations on WIOD data.

(1) Countries are ordered according to the change in their GDPX-share. Only exports of manufactures are considered.

On the other side, China and other emerging economies recorded an increase in the distance between the two shares; however, while China's GDPX-share was higher than the GX-share at the beginning of the period and even more so at the end, for other Asian economies (Korea and Taiwan in particular) and the main Eastern European exporters (Hungary, Czech Republic and Slovakia, but essentially also Poland) the GDPX-share was lower than the GX-share at the beginning of the period and even more so at the end. The gap between the two shares remains particularly large (above 1 percent, in absolute value) only for the US, China, Japan and the "Rest of the world".

\footnotetext{
${ }^{12}$ Although the levels of a country's GDPX-share and GX-share may differ.
} 


\section{Figure 4. Difference between each country's GX-share and GDPX-share: evolution between biennium 1995-96 and biennium 2010-11 (1)}

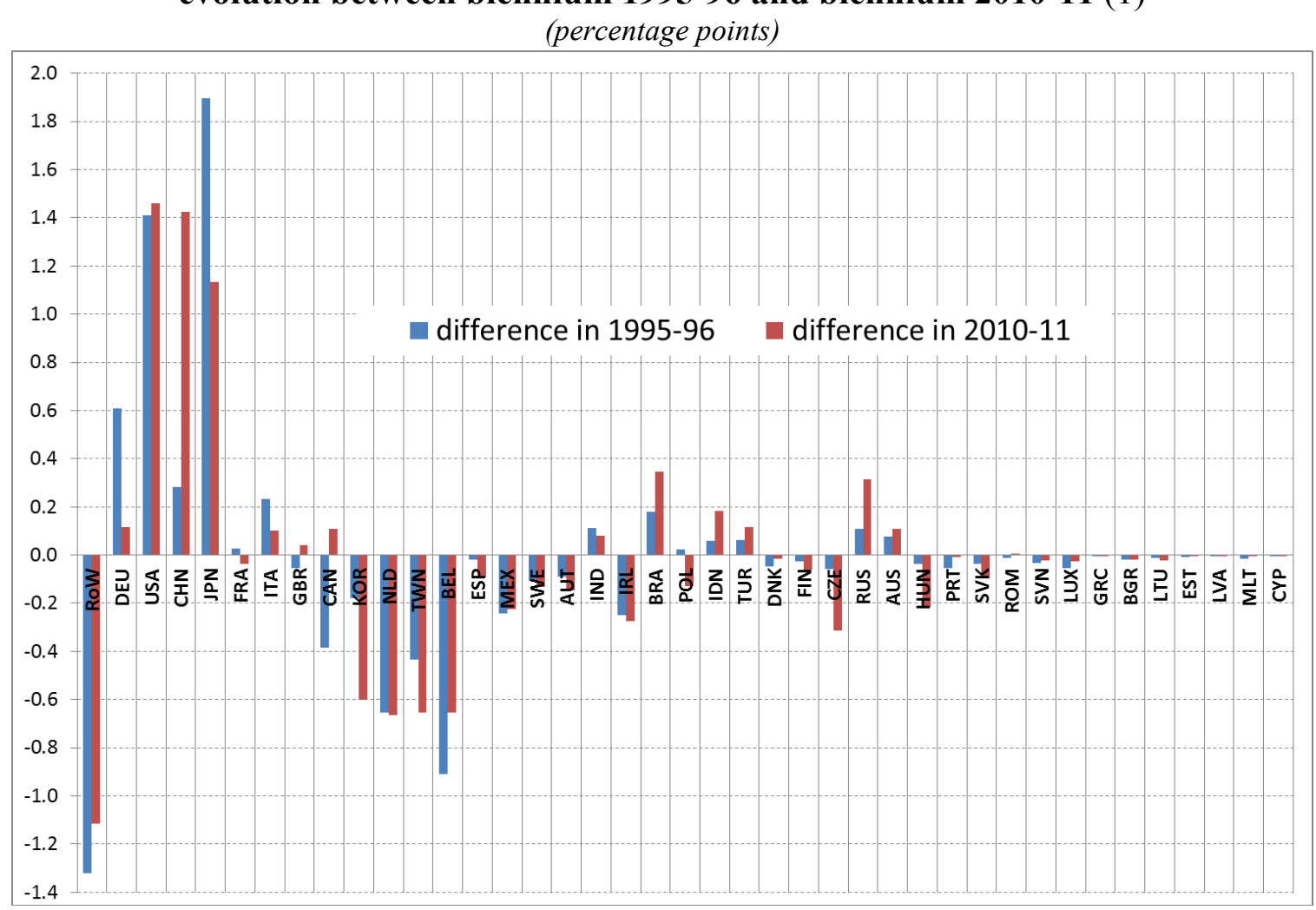

Source: authors' calculations on WIOD data.

(1) A positive (negative) bar indicates that the share in value added is larger (smaller) than the share in gross exports. Countries are ordered in terms of decreasing GX-share, averaged out over the entire sample period 1995-2011 (same ordering as in Fig. 1). Only exports of manufactures are considered.

A rough yet still useful distinction can be made by separating emerging countries from advanced economies (here, for simplicity, identified with OECD members). ${ }^{13}$ Figure 5 shows the temporal evolution of the two shares (solid line for the GX-share, dotted line for the GDPX-share; indices $1998=100$ ) for the two groups (advanced economies in red, emerging countries in black); the figure also displays the time series of the difference between the indices of the two shares, on the righthand-side axis, for each group of countries (orange bars for advanced economies, grey bars for emerging countries). While from 1997-1998 to 2004 the growth of emerging economies as surmised from market shares was stronger in gross-exports terms than in value-added terms (increasing height of grey bars in the negative quadrant), since 2004 a trend in the opposite direction has set off. The mirror-image dynamics for advanced economies show that from 1997-98 to 2004-05 their shares in value added were more resilient, whereas in the following years they contracted at a slightly faster pace than shares in gross exports. The broad message stands that the two shares tend to move together in the medium run; only in 2011 do they show changes in opposite directions, but this may be due to the preliminary nature of 2011 data in WIOD tables.

\footnotetext{
${ }^{13}$ There is of course no univocal criterion for qualifying a country as an "advanced economy". In the WEO dataset the IMF indicates 37 countries as "advanced economies". The 34 OECD members do overlap to a large extent with the set of the "advanced economies" group defined by the IMF. Only four OECD members are not classified as "advanced economies" also by the IMF: they are Hungary, Poland, Turkey and Mexico. Of the 34 OECD members, 6 are not present in the WIOD database: Chile, Iceland, Israel, New Zealand, Norway and Switzerland.
} 
Figure 5. Advanced vs emerging countries: shares dynamics and difference between GDPX-shares and GX-shares (1)

(shares as index numbers 1998=100)

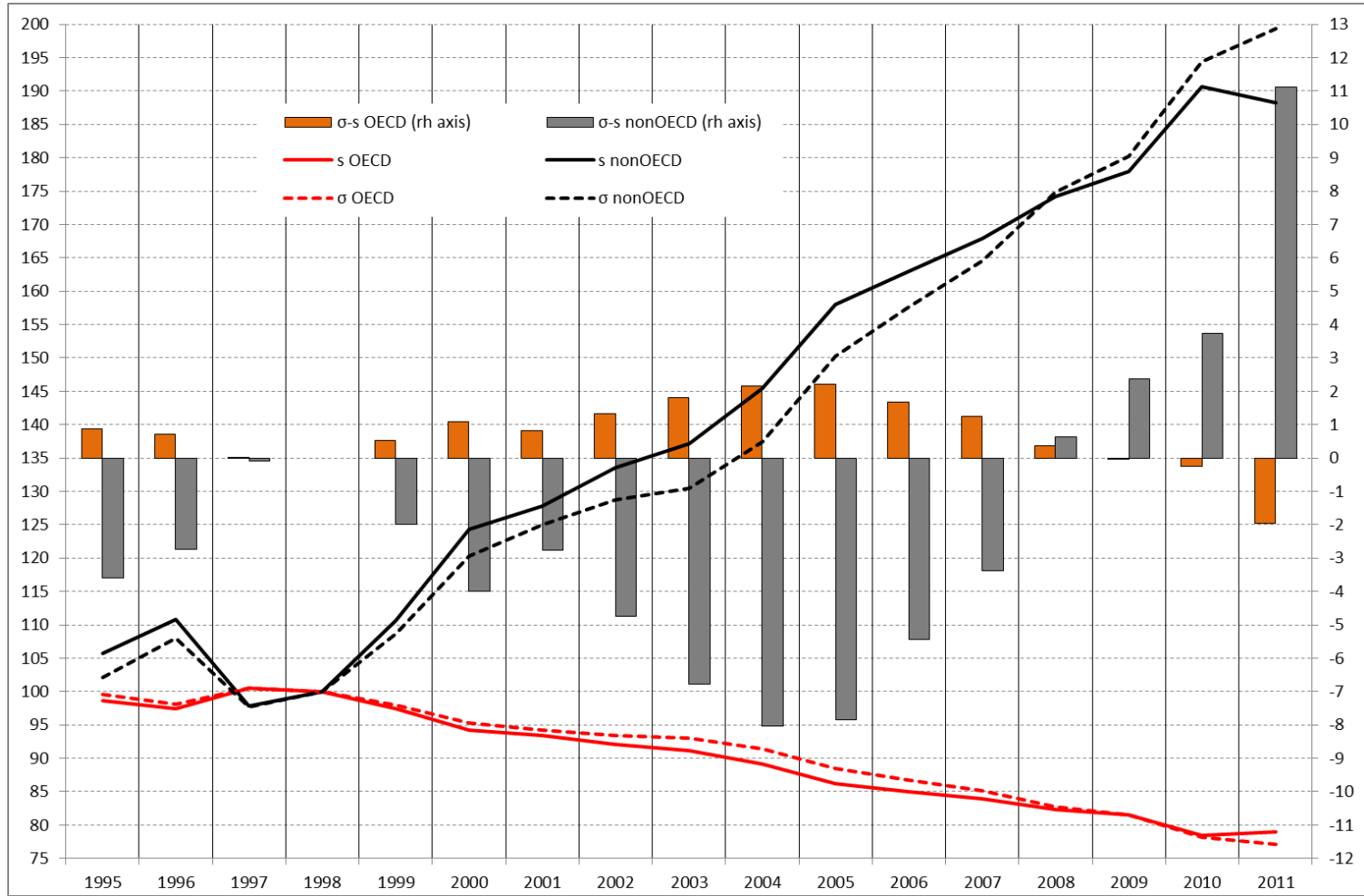

Source: authors' calculations on WIOD data.

(1) In the legend, $\sigma$ indicates the GDPX-share, $s$ indicates the GX-share, OECD indicates the aggregation of all OECD countries in the WIOD database (our proxy for advanced economies) and "nonOECD" indicates the aggregation of all remaining economies (our proxy for emerging economies). A positive bar indicates a GDPX-share larger than the GX-share. Only exports of manufactures are considered.

In summary, the year 2004 seems to mark a turning point. Until the mid-2000s, an increasing number of emerging economies progressively integrated into GVCs, predominantly as downstream assemblers; the result was a strong increase in exports coupled with a faster reduction, relative to advanced countries, in their GDPX-intensity. This process eventually met a countervailing force which had been gaining momentum: emerging economies started producing and exporting manufactures embodying a larger and larger content of domestic value added, therefore registering an increase in their GDPX-intensity relative to advanced countries and a growth of their GDPXshare faster than that of their GX-share. Commodity prices may again be playing a role, with the steep increase in oil prices suspiciously starting around 2004, as our analysis does not entirely sterilize their effects, and since natural resources tend to be concentrated in developing countries.

Aside from this caveat, a common narrative for the pivotal role of year 2004 refers to the moving position of emerging economies along the "smile curve; while the methodology we borrow from Cappariello and Felettigh (2015) is in fact able to verify whether manufacturing exports increasingly activated value added in the services sector, ${ }^{14}$ this is left for future research.

\footnotetext{
${ }^{14}$ Cappariello and Felettigh (2015) find that this tends to be the case for the largest euro-area economies.
} 


\section{A focus on the four largest euro-area countries}

We now focus on France, Germany, Italy and Spain in order to (i) take a closer look at the dynamics of their GX-shares and GDPX-shares, and (ii) provide a sectoral interpretation of the evolution of these two global market shares.

\subsection{Aggregate analysis}

Figure 6 shows that in each of the four countries the two shares tend to be very similar in levels and display almost identical medium-term dynamics over time. This is especially true for France and Spain. For Germany, ${ }^{15}$ and to a lesser extent for Italy, the GDPX-share (red bars) is always slightly higher than the GX-share (blue bars), with the difference dying off in 2010-11, although the caveat that WIOD data after 2009 are of a preliminary nature should be kept in mind. ${ }^{16}$ While shares tend to display a negative trend in France and Italy, they are basically flat in the case of Spain. German shares undergo a sharp decrease in 1999-2000, which is recovered immediately after, and a relatively larger contraction in the final years of our sample.

Relative dynamics are more evident in Figure 7, which plot shares as index numbers $(1995=100)$. The medium-term co-movement of the two shares is apparent for all countries; it is especially tight for France and Germany. For Spain, the evolution of the GDPX-share in the late 1990s was somewhat more disappointing than the evolution of the GX-share, but the opposite happened in the early 2000s. While for Germany the cumulative contraction was more pronounced in value added terms throughout the period, the shares in value added of Italy and France were more resilient than their respective shares in gross exports; up until the eve of the Great Trade Collapse in 2009, the Italian market share recorded a cumulative drop of around 15 percentage points in gross-export terms relative to Germany, only around 9.5 in value-added terms.

The picture for Germany and Spain being somewhat less favourable, in relative terms, when evaluated on the basis of GDPX-shares may be the flip-side of the stronger resilience of both their market shares, relative to France and Italy, if a larger drop in GDPX-intensity, due to deeper involvement into GVCs and better availability of "cheap intermediates", was associated with faster competitiveness gains which in turn sustained the trajectory of both their GX-shares and GDPXshares. Policy evaluations should take into account the existence of such likely trade-off between GDPX-intensity and market shares dynamics: a higher GDPX-intensity is good for GDP growth (in expansionary phases); on the other side, defending export market shares may require a deeper involvement into GVCs, which tends to lower the country's GDPX-intensity.

On the other hand, increasing a country's GDPX-intensity need not be beneficial for its GDP growth: while given a positive shock to foreign demand and the ensuing increase in a country's exports, a larger GDPX-intensity translates into a larger rise in GDP, one also needs to consider the counterfactual scenario where a decreasing GDPX-intensity (that was associated with gains in price and non-price competitiveness) would have enabled a larger increase in gross exports. We will come back to this point in the last part of this section, when dealing with the sectoral analysis.

The information summarized in Figures 6-7 can be re-cast in terms of GDPX-intensities, as explained in Section 2. Figure 8 plots the GDPX-intensities of our four countries, together with the world average and, as a further benchmark, the average of the remaining euro-area member states. All countries show a declining trend in their GDPX-intensity, with fluctuations following closely those of the world average. The GDPX-intensity of Italy is the highest, while that of Spain is the lowest and the only one below the world average. The large gap between the GDPX-intensity of the four main euro-area countries and the average for the rest of the euro area reflects, in particular, the weight of Netherlands, Belgium and Ireland, small open economies characterised by particularly low GDPX-intensities, as already shown in Section 3.1.

\footnotetext{
${ }^{15}$ For Germany, only the extension of the scale in the graph is uniform relative to the other three countries.

${ }^{16}$ In percentage terms, the difference between the two shares is higher in Italy than in Germany.
} 
Figure 6. GX-shares and GDPX-shares for the four largest euro-area countries (1) (percentage points)

Italy

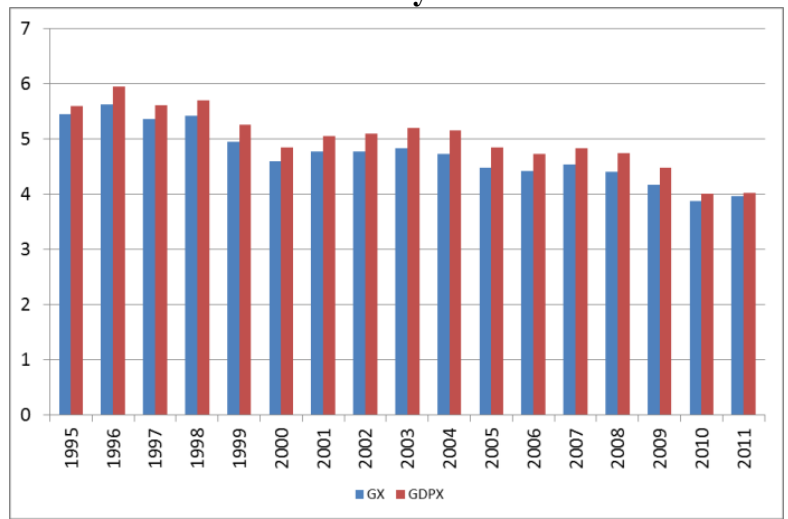

France

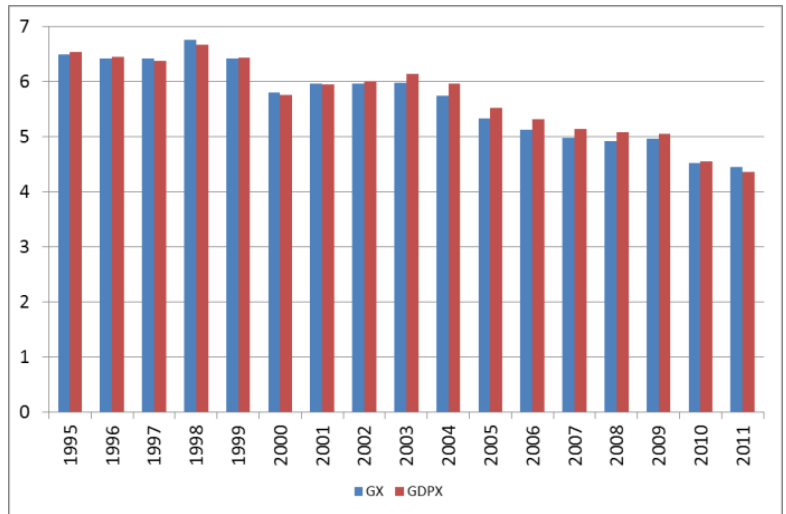

Germany (2)

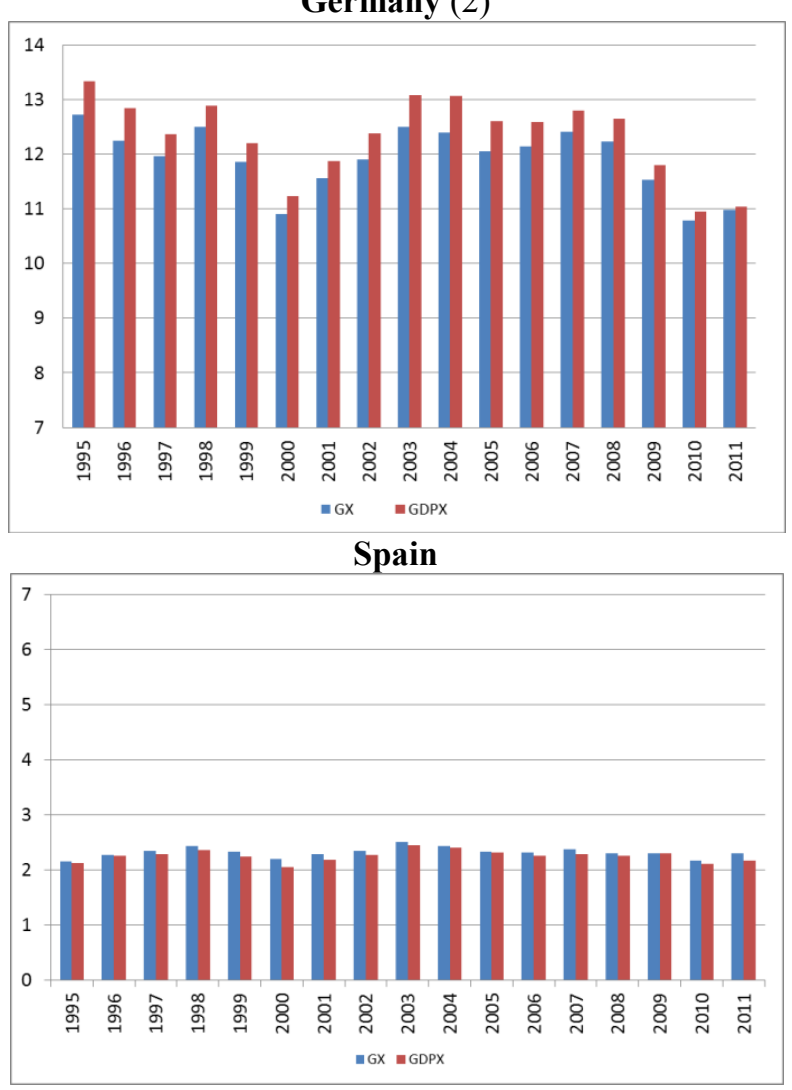

Source: authors' calculations on WIOD data.

(1) Only exports of manufactures are considered.

(2) Differently from the other countries, for Germany the scale on the left-hand-side axis begins at 7 rather than 0 .

Figure 7. Dynamics in market shares in value added and in manufacturing gross exports (index numbers $1995=100$ )

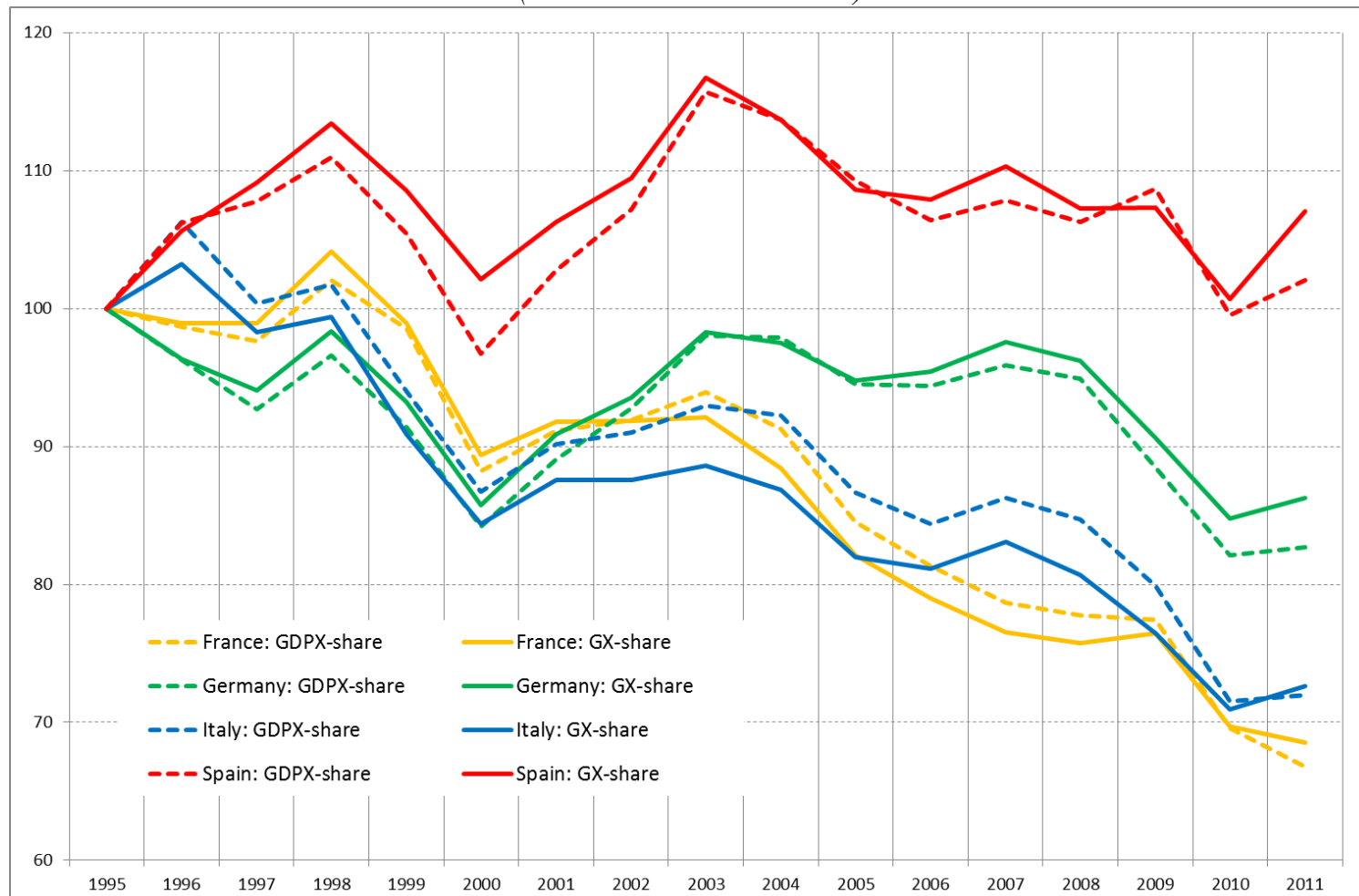

Source: authors' calculations on WIOD data. 
Figure 8. GDPX-intensities over time (1)

(percentage points)

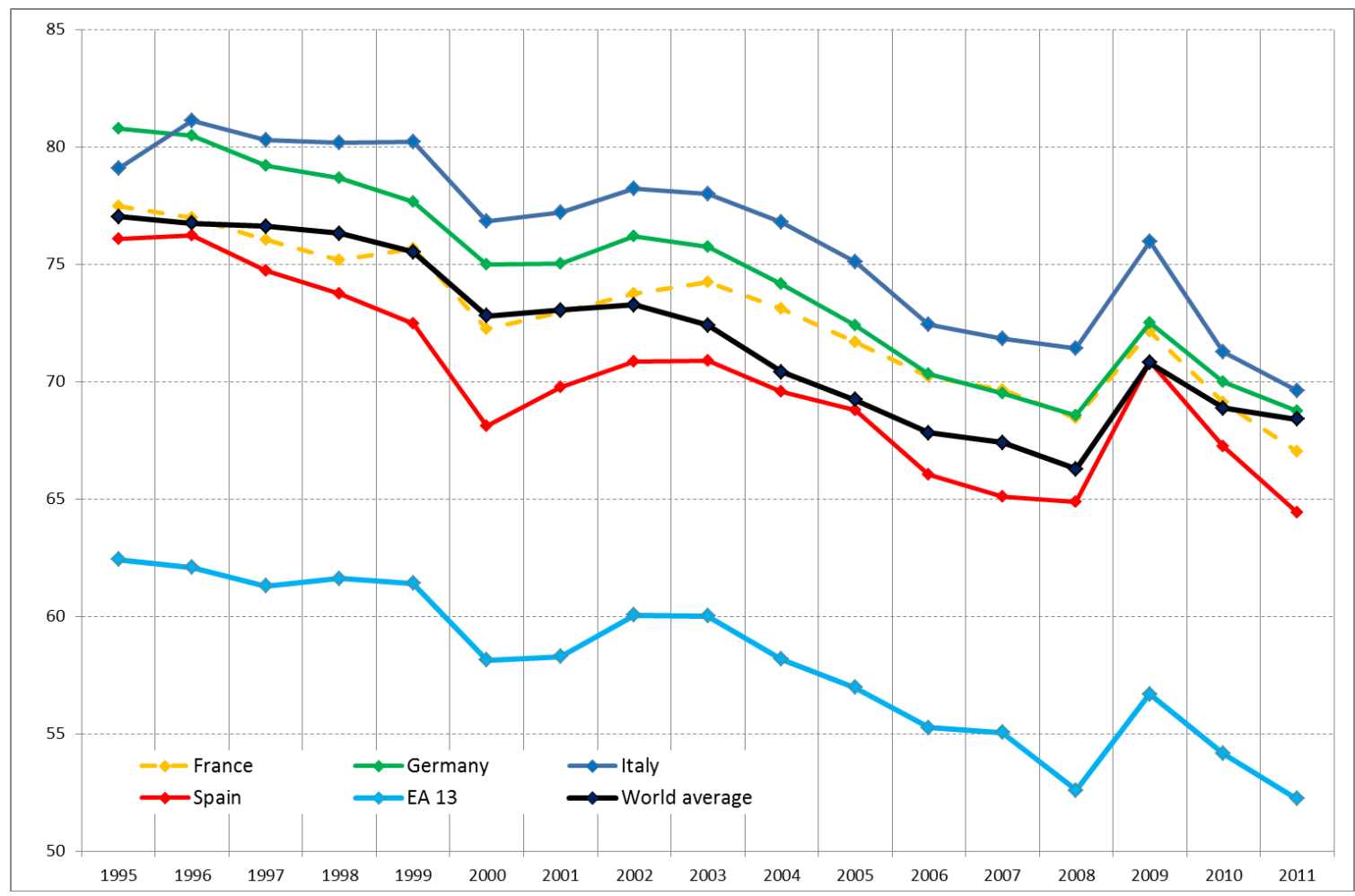

Source: authors' calculations on WIOD data.

(1) Only exports of manufactures are considered.

Notes: EA13 is the euro area with 17 members less France, Germany, Italy and Spain.

\subsection{Analysis by sector}

Explaining the dynamics of countries' market shares in gross exports and in value added ${ }^{17}$ is beyond the descriptive scope of this paper. Some economic interpretation can however be put forth thanks to the sectoral detail of WIOD tables. In particular, Figure 8 has shown that GDPXintensities in each of the largest euro-area countries fell along a descending trend between 1995 and 2011. A natural question that arises is whether, in a shift-share analysis framework, such changes are mostly due to variations in sectoral GDPX-intensities or rather to changes in the sectoral composition. For example, was Italy's drop in GDPX-intensity (around 10 percentage points) mostly driven by the fact that Italy became increasingly specialised in sectors with a low GDPXintensity? Or was it mostly due to the fact that in 1995 Italy was specialized in sectors that were set to record the biggest contraction in GDPX-intensity in the years to follow? A direct answer to such questions can be given by an algebraic decomposition of the aggregate GDPX-intensity of a country, which is indeed an average of the GDPX-intensities of the various economic sectors $k\left(\gamma_{k}\right)$, weighted by the sectoral shares in gross exports $\left(s_{k}\right)$ :

$$
\gamma=\sum_{k} s_{k} \gamma_{k}
$$

The total variation as of an initial year $t_{0}$ (indicated by the operator $\Delta$ ) can then be decomposed into three terms:

$$
\Delta \gamma=\sum_{k} s_{k}^{t_{0}} \cdot \Delta \gamma_{k}+\sum_{k} \Delta s_{k} \cdot \gamma_{k}^{t_{0}}+\sum_{k} \Delta s_{k} \cdot \Delta \gamma_{k}
$$

\footnotetext{
${ }^{17}$ See Benkovskis and Wörz (2015) for a contribution along these lines.
} 
The three terms are:

1. a partial variation due to the shifts of the sectoral GDPX-intensities, measuring the change in $\gamma$ that would have been observed had the sectoral composition of exports remained constant since $t_{0}$ ("change in GVC-participation effect");

2. a partial variation due to changes in the sectoral composition of exports, measuring the change in $\gamma$ that would have been observed had the sectoral GDPX-intensities remained constant at their initial levels ("change in specialisation effect");

3. an interaction term capturing the second-order effect of simultaneous changes in shares and in GDPX-intensities ("interaction effect").

The results of our decomposition are presented in Figure 9. Two regularities emerge: (i) all three effects have a negative sign, i.e. they all contributed to the fall in aggregate GDPX-intensities, and (ii) the first effect ("change in GVC-participation", capturing the pervasive fall in sectoral GDPXintensities) is largely dominant, as it accounts for a proportion of the observed change in the aggregate GDPX-intensity ranging from an almost totalitarian $98 \%$ for Germany to an hefty $71 \%$ for Italy (Table 1 details percentage contributions).

Figure 9. Decomposition of changes in aggregate GDPX-intensities between biennia 1995-96 and 2010-11 (1)

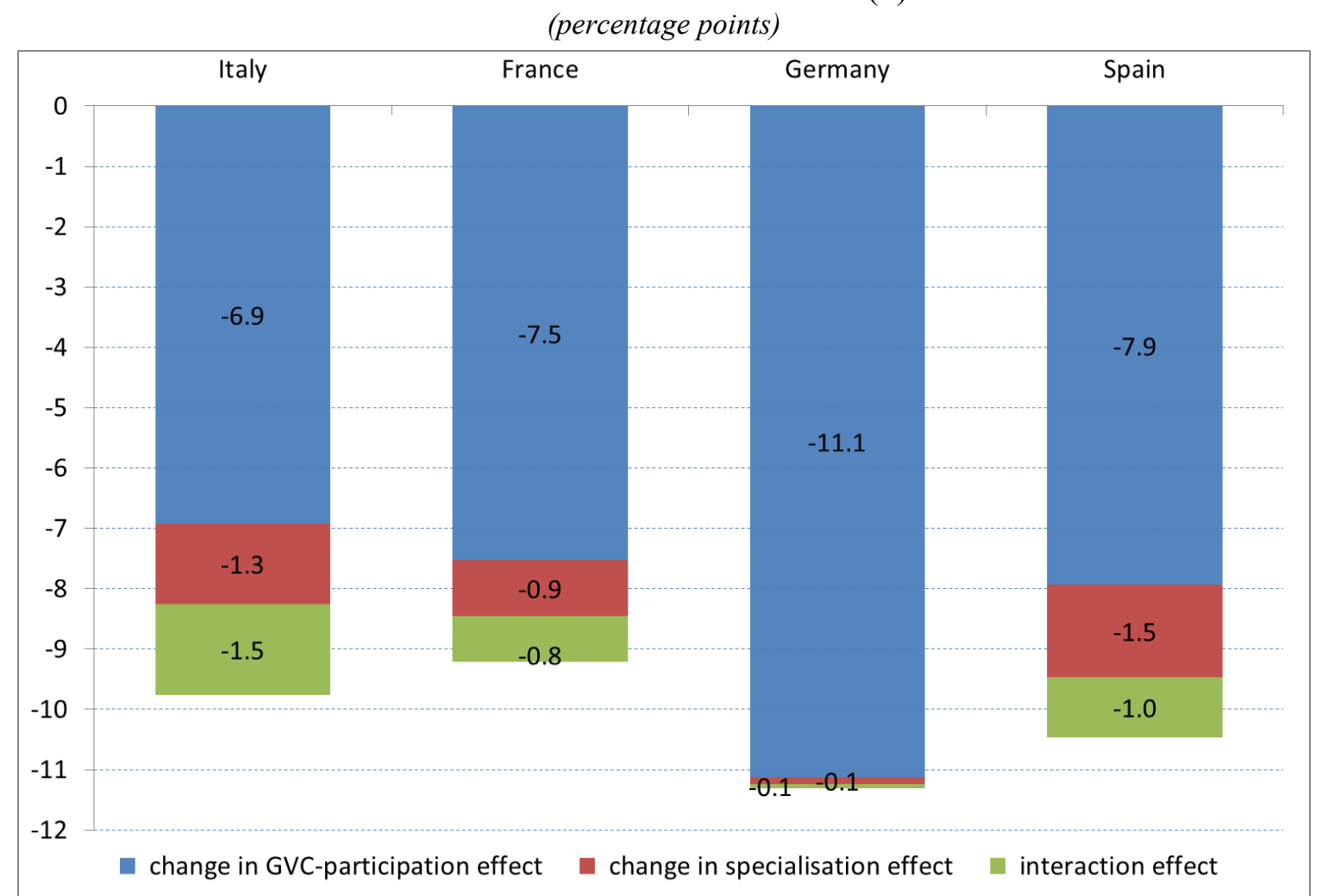

Source: authors' calculations on WIOD data.

(1) Only exports of manufactures are considered.

The "change in specialisation effect" is negligible for Germany, while it weighs between 10 and $15 \%$ for the other three countries, which still translates into modest contributions: had Italy kept its sectoral composition unchanged since 1995-96, its overall GDPX-intensity in 2010-11 would have been 1.3 percentage points higher $(71.7 \%$ instead of $70.4 \%)$. The three effects displayed in Figure 9 , that is the three components of equation (5), can be broken down into sectoral contributions (i.e. the addends in each summation). We focus exclusively on the first term ("change in GVC-participation effect"), given its predominance (Figure 10; see Table A1 in the Appendix for evidence on unweighted sectoral GDPX-intensities shifts). 
Table 1. Decomposition of changes in aggregate GDPX-intensities between biennia 1995-96 and 2010-11 (1)

(percentage points)

\begin{tabular}{l|c|ccc}
\hline Countries & $\begin{array}{c}\text { Total variation } \\
\text { in GDPX- } \\
\text { intensity }\end{array}$ & $\begin{array}{c}\text { Change in GVC- } \\
\text { participation } \\
\text { effect }\end{array}$ & $\begin{array}{c}\text { Change in } \\
\text { specialisation } \\
\text { effect }\end{array}$ & $\begin{array}{c}\text { Interaction } \\
\text { effect }\end{array}$ \\
\hline France & $\mathbf{- 9 . 2}$ & -7.5 & Contributions of the three effects \\
Germany & $\mathbf{- 1 1 . 3}$ & -11.1 & -0.9 & -0.8 \\
Italy & $\mathbf{- 9 . 8}$ & -6.9 & -0.1 & -0.1 \\
Spain & $\mathbf{- 1 0 . 5}$ & -7.9 & -1.3 & -1.5 \\
\hline & & Percentage contributions of the three effects \\
France & $\mathbf{- 1 0 0}$ & -81.8 & -10.0 & -8.2 \\
Germany & $\mathbf{- 1 0 0}$ & -98.4 & -1.0 & -0.6 \\
Italy & $\mathbf{- 1 0 0}$ & -70.9 & -13.7 & -15.4 \\
Spain & $\mathbf{- 1 0 0}$ & -75.9 & -14.6 & -9.5 \\
\hline
\end{tabular}

Source: authors' calculations on WIOD data.

(1) Only exports of manufactures are considered.

Five sectors played a major role in the fall of GDPX-intensities in all four countries: (i) transport equipment, (ii) electrical and electronic equipment, (iii) machinery, (iv) chemicals and pharmaceutical products and (v) basic and fabricated metals. These five sectors account for $83 \%$ of the overall "change in GVC-participation effect" in Germany, 77\% in France, 72\% in Spain, 63\% in Italy. These cumulative shares for Spain and Italy are smaller because for these countries the weight of refined oil products is also relevant (together with the weight of textiles, in the case of Italy).

Figure 10. "Change in GVC-participation effect": sectoral contributions (1) (percentage points)

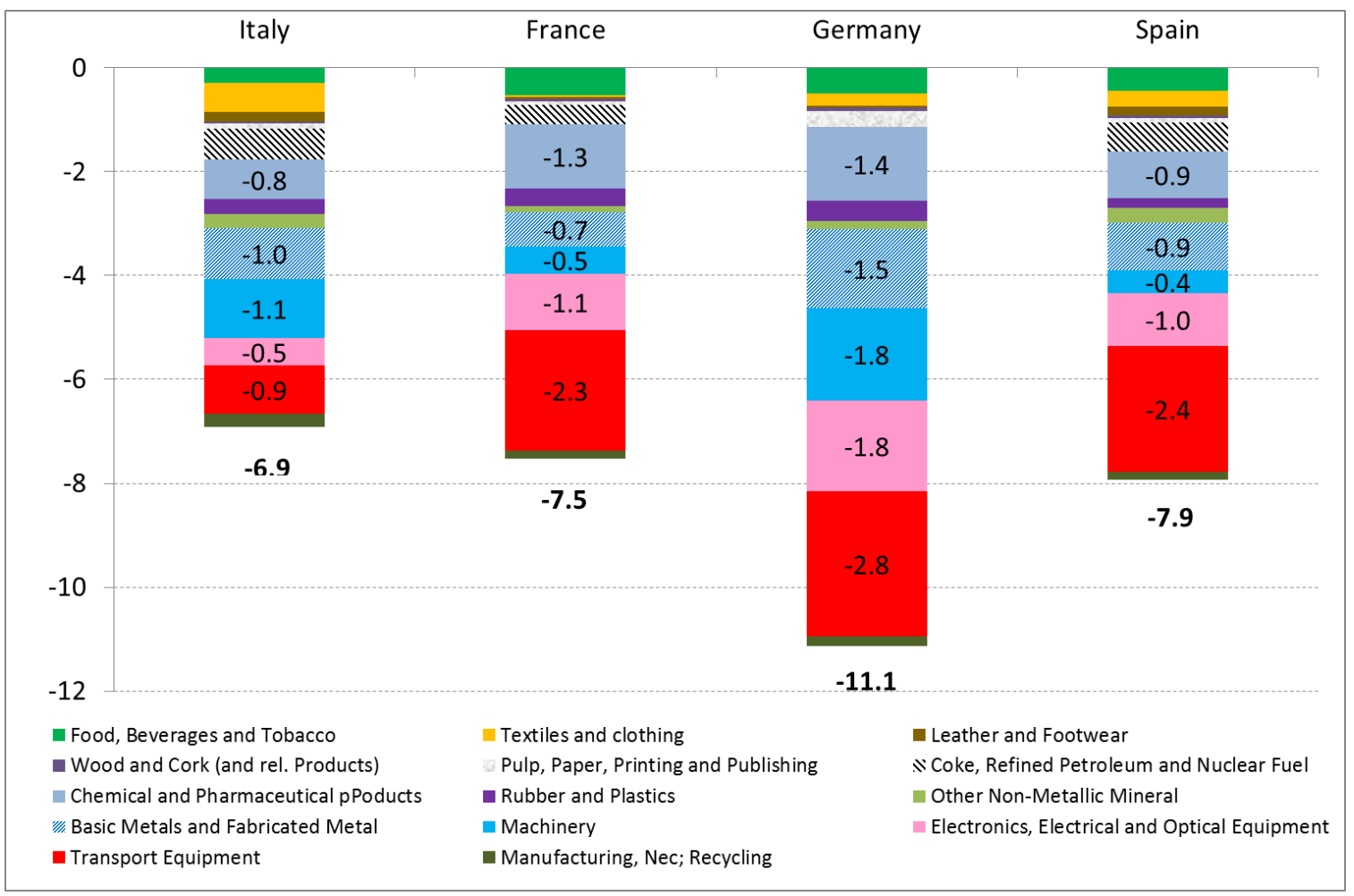

Source: author's calculations on WIOD data.

(1) Only exports of manufactures are considered. 
The evolution of national GDPX-intensities in the main sectors is reported in Figure 11, where averages for relevant groups of benchmark countries were also added: euro-area member states other than France, Germany, Italy and Spain, the OECD group and the world average. All four countries tend to display GDPX-intensities consistently above the world average in all sectors, with a few exceptions: transport equipment in Spain and France (and, especially in recent years, Germany), chemical and pharmaceutical products in Italy, textiles (as well as basic and fabricated metal products, especially in the 2000s) in Germany.

Table 2 offers a wider perspective on sectoral GDPX-intensities across all manufacturing sectors, enlarging the view presented in Figure 11. The country-sector cells reporting a GDPX-intensity higher than the world average have been shaded in light blue. Apart from the US, Japan and China, which display GDPX-intensities higher than the world-average in virtually all sectors, Italy and the United Kingdom have the largest number of sectors where their GDPX-intensity is higher than the global average. Spain, which was the country with the highest number of sectors with a GDPXintensity below the global average, was replaced by Germany at the end of the period. Drops in GDPX-intensities took place in the vast majority of country-sector pairs; according to the world average, they were particularly sharp in the sectors of refined petroleum (no. 8 in Table 2), chemical and pharmaceutical products (no. 9), metal products (no. 12), machinery (no. 13) and transport equipment (no. 15). Many of these productions make intensive use of raw materials and their GDPX-intensity was thus penalized by the surge in commodity prices that took place during the 2000s. The transport equipment sector (no. 15) is often characterized as one of those more exposed to the diffusion of GVCs, with GDPX-intensities decreasing the most in Germany, France and the US. On the other hand, traditional sectors seem to show GDPX-intensities that are higher and declined less than the average (across products).

Figure 12 brings the focus back on the four largest euro-area economies to show that there is a (statistically significant) negative relationship between medium-term changes in the sectoral composition of exports and medium-term changes in sectoral GDPX-intensities. On average, when a sector increases its share in a country's gross exports by 1 percentage point, its GDPX-intensity falls by 1.2 percentage points. ${ }^{18}$ Although we cannot identify the direction of causality, a lesson emerges: the sectors whose exports grew faster than the national average in the last fifteen years or so are also the sectors whose GDPX-intensity fell the most, which tends to signal that their involvement into GVCs was more dynamic than the average, possibly entailing improved competitiveness via outsourcing of intermediates inputs from abroad at cheaper prices (or of better quality).

Such empirical regularity at the sectoral level (sectors within a country) matches the interpretation we have proposed at the geographical level (countries within the euro area). To summarize, in a comparative static framework a larger GDPX-intensity translates into a larger rise in GDP, given a positive shock to foreign demand and the ensuing increase in a country's or a sector's exports. Our empirical findings, however, seem to indicate that in a dynamic framework, one should also consider that higher (or more resilient) GDPX-intensities tend to be associated with a lower degree of involvement into GVCs, more limited access to "competitive" intermediate inputs and, ultimately, worse gross export performance: the increase in exports following the given positive shock to foreign demand tends to be smaller for countries/sectors with a high GDPX-intensity. According to our sectoral analysis, though, the static effect still prevails (namely higher or more resilient GDPX-intensities are good for GDP growth, after all), as the dynamic medium-term tradeoff is on average between an increase in the GDPX-intensity and a less than proportionate decrease in the export share.

\footnotetext{
${ }^{18}$ The OLS slope is -1.18 , with p-value below $0.5 \%$. Equivalently, the correlation coefficient between changes in sectoral export shares and changes in sectoral GDPX-shares is 0.76 .
} 
Figure 11. Sectoral GDPX-intensities: time-averages for the main manufacturing sectors (percentage points)
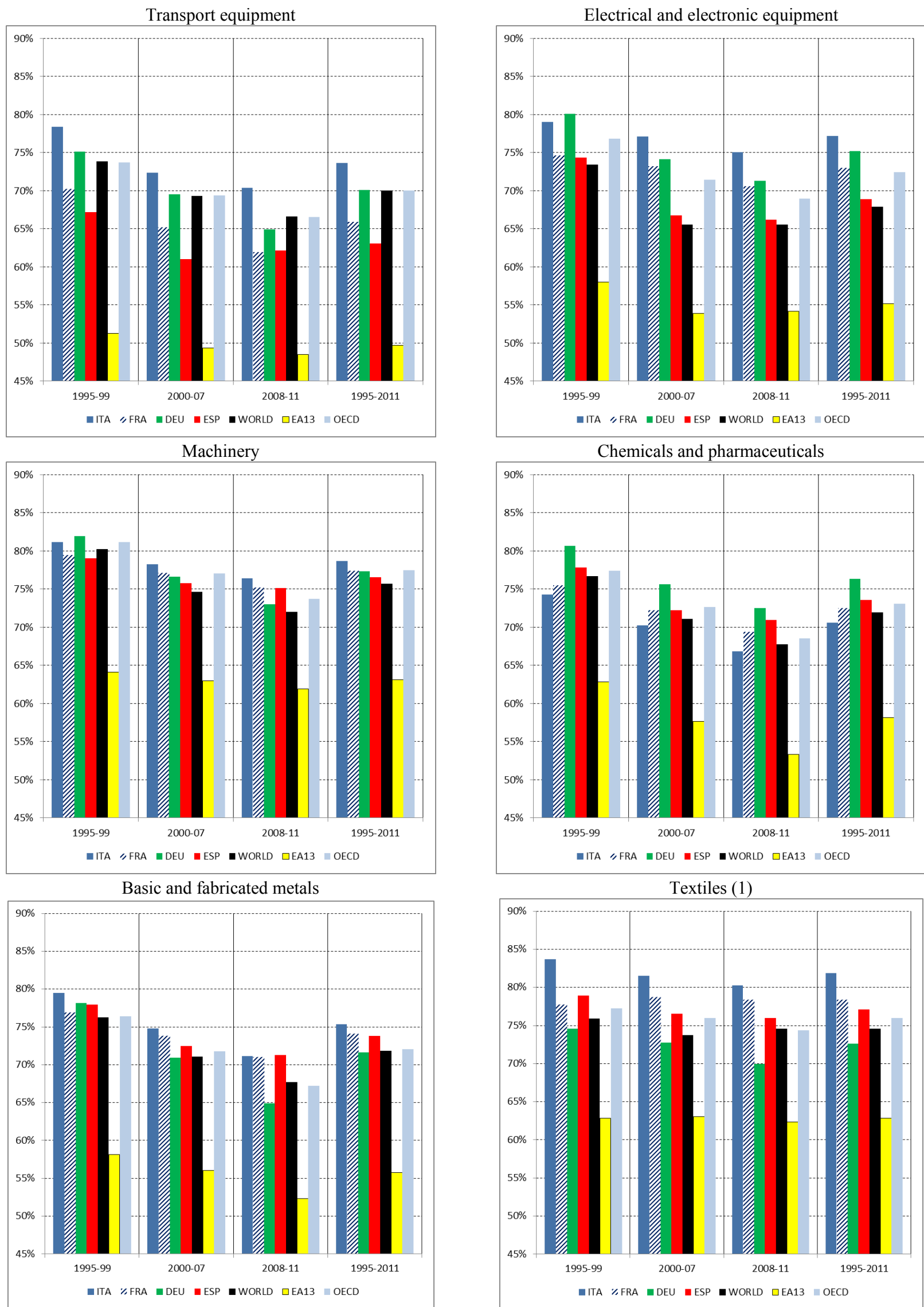

Source: authors' calculation on WIOD data

(1) In the text the "Coke, refined petroleum and nuclear fuel sector" is also mentioned, but it is not represented here due to out-of-scale values. 
Table 2. Sectoral GDPX-intensities by country/area and by manufacturing sector (percentage points)

Average in 1995-2011

\begin{tabular}{lccccccccccccccc}
\hline & 3 & 4 & 5 & 6 & 7 & 8 & 9 & 10 & 11 & 12 & 13 & 14 & 15 & 16 & TOT \\
\hline ITA & 83.3 & 81.9 & 82.3 & 81.0 & 81.6 & 35.8 & 70.6 & 74.8 & 82.9 & 75.3 & 78.6 & 77.2 & 73.7 & 78.8 & 76.2 \\
\hline FRA & 84.8 & 78.3 & 80.9 & 81.8 & 80.2 & 43.7 & 72.5 & 73.9 & 83.3 & 74.1 & 77.4 & 73.0 & 65.9 & 78.1 & 72.7 \\
\hline DEU & 80.7 & 72.6 & 72.4 & 78.7 & 81.4 & 57.9 & 76.4 & 75.8 & 82.7 & 71.6 & 77.3 & 75.2 & 70.1 & 79.0 & 74.4 \\
\hline ESP & 82.0 & 77.1 & 77.2 & 79.0 & 80.0 & 35.1 & 73.6 & 73.7 & 82.3 & 73.8 & 76.6 & 68.9 & 63.1 & 77.1 & 70.0 \\
\hline GBR & 85.3 & 79.0 & 85.0 & 79.0 & 84.9 & 67.9 & 77.6 & 80.1 & 82.8 & 75.7 & 76.7 & 72.3 & 68.4 & 78.7 & 74.8 \\
\hline USA & 88.9 & 86.1 & 82.8 & 87.4 & 90.1 & 65.3 & 84.5 & 84.6 & 89.9 & 84.5 & 84.7 & 85.3 & 79.1 & 87.8 & 83.5 \\
\hline CHN & 90.8 & 83.2 & 83.1 & 85.3 & 84.1 & 70.2 & 80.1 & 79.2 & 86.4 & 79.8 & 80.7 & 71.0 & 80.5 & 86.0 & 77.9 \\
\hline JPN & 92.3 & 90.7 & 92.4 & 86.9 & 93.0 & 59.9 & 86.5 & 89.5 & 87.2 & 84.7 & 88.9 & 88.3 & 89.5 & 90.0 & 87.7 \\
\hline EA13 & 66.5 & 62.8 & 67.3 & 71.6 & 66.8 & 36.8 & 58.2 & 60.7 & 70.6 & 55.8 & 63.1 & 55.2 & 49.7 & 65.3 & 58.0 \\
\hline EA17 & 75.7 & 73.9 & 78.1 & 75.4 & 74.6 & 40.6 & 68.5 & 71.2 & 79.4 & 67.7 & 74.8 & 68.8 & 65.4 & 74.8 & 69.3 \\
\hline OECD & 79.2 & 76.0 & 78.1 & 79.4 & 79.3 & 48.5 & 73.1 & 74.5 & 81.2 & 72.1 & 77.5 & 72.4 & 70.0 & 77.5 & 72.9 \\
\hline WORLD & $\mathbf{8 0 . 4}$ & $\mathbf{7 4 . 6}$ & $\mathbf{7 7 . 5}$ & $\mathbf{7 9 . 3}$ & $\mathbf{7 9 . 3}$ & $\mathbf{5 9 . 5}$ & $\mathbf{7 1 . 9}$ & $\mathbf{7 4 . 1}$ & $\mathbf{8 0 . 5}$ & $\mathbf{7 1 . 8}$ & $\mathbf{7 5 . 7}$ & $\mathbf{6 7 . 9}$ & $\mathbf{7 0 . 0}$ & $\mathbf{7 4 . 9}$ & $\mathbf{7 1 . 9}$ \\
\hline
\end{tabular}

Average in 2010-11

\begin{tabular}{lrrrrrrrrrrrrrrr}
\hline & \multicolumn{1}{c}{3} & \multicolumn{1}{c}{4} & \multicolumn{1}{c}{5} & \multicolumn{1}{c}{6} & \multicolumn{1}{c}{$\mathbf{7}$} & \multicolumn{1}{c}{9} & \multicolumn{1}{c}{10} & 11 & 12 & 13 & 14 & \multicolumn{1}{c}{15} & \multicolumn{1}{c}{16} & TOT \\
\hline ITA & 79.7 & 79.1 & 80.3 & 78.2 & 78.7 & 14.4 & 65.1 & 70.5 & 78.7 & 69.7 & 75.5 & 73.1 & 69.5 & 76.9 & 70.4 \\
\hline FRA & 81.6 & 77.3 & 79.8 & 78.2 & 78.7 & 38.4 & 68.1 & 68.1 & 80.3 & 69.7 & 74.6 & 68.5 & 60.6 & 74.7 & 68.1 \\
\hline DEU & 74.7 & 69.3 & 70 & 73.5 & 77.9 & 68.4 & 72.2 & 70.7 & 79.4 & 64.2 & 72.3 & 70 & 64 & 74.4 & 69.4 \\
\hline ESP & 80 & 73.9 & 75.3 & 79.1 & 79.6 & 24.9 & 70.2 & 71.5 & 80.2 & 70.2 & 74.7 & 65.6 & 61 & 75.4 & 65.8 \\
\hline GBR & 83.7 & 77.3 & 82.8 & 78.5 & 83.8 & 48.7 & 74.5 & 77.3 & 80.9 & 68.8 & 71.7 & 70.3 & 62.5 & 75.7 & 69.5 \\
\hline USA & 86.4 & 80.9 & 83.2 & 86.5 & 88.1 & 57.2 & 80.6 & 81.3 & 87 & 80.3 & 82.7 & 88 & 72 & 86.3 & 79.8 \\
\hline CHN & 88.9 & 85.5 & 85.2 & 83.7 & 81.6 & 59 & 76.4 & 77.1 & 83.7 & 73.7 & 77.6 & 69.4 & 77.7 & 85.5 & 75.7 \\
\hline JPN & 89.6 & 88.4 & 89.6 & 84.8 & 91.1 & 48.3 & 80.3 & 83.8 & 80.1 & 76.6 & 84.5 & 84.1 & 84.8 & 85.4 & 81.9 \\
\hline EA13 & 62.9 & 61.9 & 66.5 & 69.5 & 62.9 & 22.8 & 53 & 59.2 & 67.9 & 51.5 & 61.9 & 54.4 & 48.5 & 63.3 & 53.2 \\
\hline EA17 & 71.8 & 72.1 & 76.8 & 72.5 & 71.7 & 29.2 & 63.9 & 67.5 & 76.2 & 62.3 & 71.2 & 65.9 & 61.2 & 72.0 & 64.4 \\
\hline OECD & 76 & 73.6 & 76.5 & 76.7 & 76.9 & 39.8 & 68.1 & 71 & 78.1 & 66.7 & 73.5 & 68.8 & 65.9 & 75.2 & 68.1 \\
\hline WORLD & $\mathbf{7 9 . 1}$ & $\mathbf{7 3 . 9}$ & $\mathbf{7 8 . 6}$ & $\mathbf{7 8 . 4}$ & $\mathbf{7 7 . 5}$ & $\mathbf{5 3 . 1}$ & $\mathbf{6 8 . 2}$ & $\mathbf{7 1 . 4}$ & $\mathbf{7 8 . 4}$ & $\mathbf{6 8 . 1}$ & $\mathbf{7 1 . 9}$ & $\mathbf{6 5 . 7}$ & $\mathbf{6 6 . 3}$ & $\mathbf{7 0 . 7}$ & $\mathbf{6 8 . 6}$ \\
\hline
\end{tabular}

Percentage difference between average in biennium 2010-11 and average in biennium 1995-96

\begin{tabular}{lccccccccccccccc}
\hline & 3 & 4 & 5 & 6 & 7 & 8 & 9 & 10 & 11 & 12 & 13 & 14 & 15 & 16 & TOT \\
\hline ITA & -5.5 & -4.8 & -3.2 & -5.3 & -4.2 & -40.0 & -9.2 & -7.1 & -6.8 & -9.5 & -5.4 & -5.4 & -8.8 & -3.9 & -9.7 \\
\hline FRA & -4.8 & -0.6 & -3.7 & -7.5 & -2.1 & -21.1 & -7.9 & -9.7 & -5.8 & -7.3 & -5.5 & -7.1 & -11.3 & -6.5 & -9.2 \\
\hline DEU & -10.4 & -6.1 & -6.6 & -11.5 & -7.8 & 1.0 & -10.1 & -10.6 & -9.1 & -14.3 & -10.6 & -11.2 & -13.1 & -9.7 & -11.3 \\
\hline ESP & -5.0 & -6.5 & -5.9 & -5.8 & -2.7 & -21.0 & -8.6 & -5.5 & -7.0 & -9.4 & -5.9 & -10.7 & -8.0 & -6.3 & -10.3 \\
\hline GBR & -0.8 & 0.2 & -3.6 & 1.2 & 0.6 & -27.6 & -3.5 & -1.8 & -2.2 & -8.5 & -6.1 & -2.0 & -8.3 & -2.4 & -6.6 \\
\hline USA & -3.9 & -8.1 & -1.0 & -2.4 & -2.6 & -13.9 & -7.6 & -6.5 & -4.7 & -6.8 & -4.3 & 3.5 & -10.6 & -3.4 & -6.1 \\
\hline CHN & -3.4 & 2.3 & 2.6 & -1.8 & -4.8 & -20.7 & -8.7 & -5.6 & -5.9 & -11.4 & -8.3 & -9.2 & -6.7 & -0.3 & -7.6 \\
\hline JPN & -4.6 & -5.1 & -4.8 & -4.2 & -3.9 & -36.1 & -13.2 & -10.5 & -12.1 & -15.3 & -9.4 & -9.0 & -9.6 & -8.1 & -11.5 \\
\hline EA13 & -6.1 & -1.1 & -4.3 & -5.6 & -7.0 & -25.3 & -10.8 & -2.3 & -4.5 & -6.8 & -2.5 & -4.6 & -2.5 & -3.1 & -9.1 \\
\hline EA17 & -6.1 & -2.5 & -3.7 & -6.9 & -5.5 & -23.6 & -10.1 & -6.7 & -6.5 & -9.7 & -7.5 & -7.7 & -9.3 & -5.5 & -9.9 \\
\hline OECD & -5.3 & -3.8 & -3.9 & -6.2 & -4.8 & -18.7 & -10.0 & -6.7 & -6.1 & -10.1 & -8.3 & -9.2 & -8.9 & -4.6 & -9.9 \\
\hline WORLD & $-\mathbf{3 . 0}$ & $-\mathbf{2 . 1}$ & $-\mathbf{- 0 . 5}$ & $-\mathbf{3 . 3}$ & $-\mathbf{4 . 2}$ & -14.1 & $-\mathbf{8 . 7}$ & $-\mathbf{- 5 . 7}$ & $-\mathbf{- 5 . 7}$ & $-\mathbf{8 . 3}$ & $-\mathbf{8 . 6}$ & $-\mathbf{8 . 3}$ & $-\mathbf{8 . 6}$ & $-\mathbf{- 7 . 8}$ & $-\mathbf{8 . 3}$ \\
\hline
\end{tabular}

\section{WIOD Codes for sectors}

3 Food, beverages and tobacco

$4 \quad$ Textiles and clothing

$5 \quad$ Leather and footwear

$6 \quad$ Wood and cork (and rel. products)

$7 \quad$ Pulp, paper, printing and publishing

8 Coke, refined petroleum and nuclear fuel

9 Chemical and pharmaceutical products

10
11 Other non-metallic mineral products

12 Basic metals and fabricated metal

13 Machinery

14 Electronics, electrical and optical equipment

15 Transport equipment

16 Manufacturing n.e.c. and recycling

TOT Total manufacturing

Source: author's calculations on WIOD data.

Notes: EA17 is the euro area with 17 members; EA13 is EA17 less France, Germany, Italy and Spain. Shaded cells indicate values of the sectoral GDPX-intensity larger than the world average for that sector, i.e. countries having a sectoral share in value added larger than the corresponding share in gross exports. 
Fig. 12. Sectoral GDPX-intensity and sectoral specialisation (1)

(percentage points)

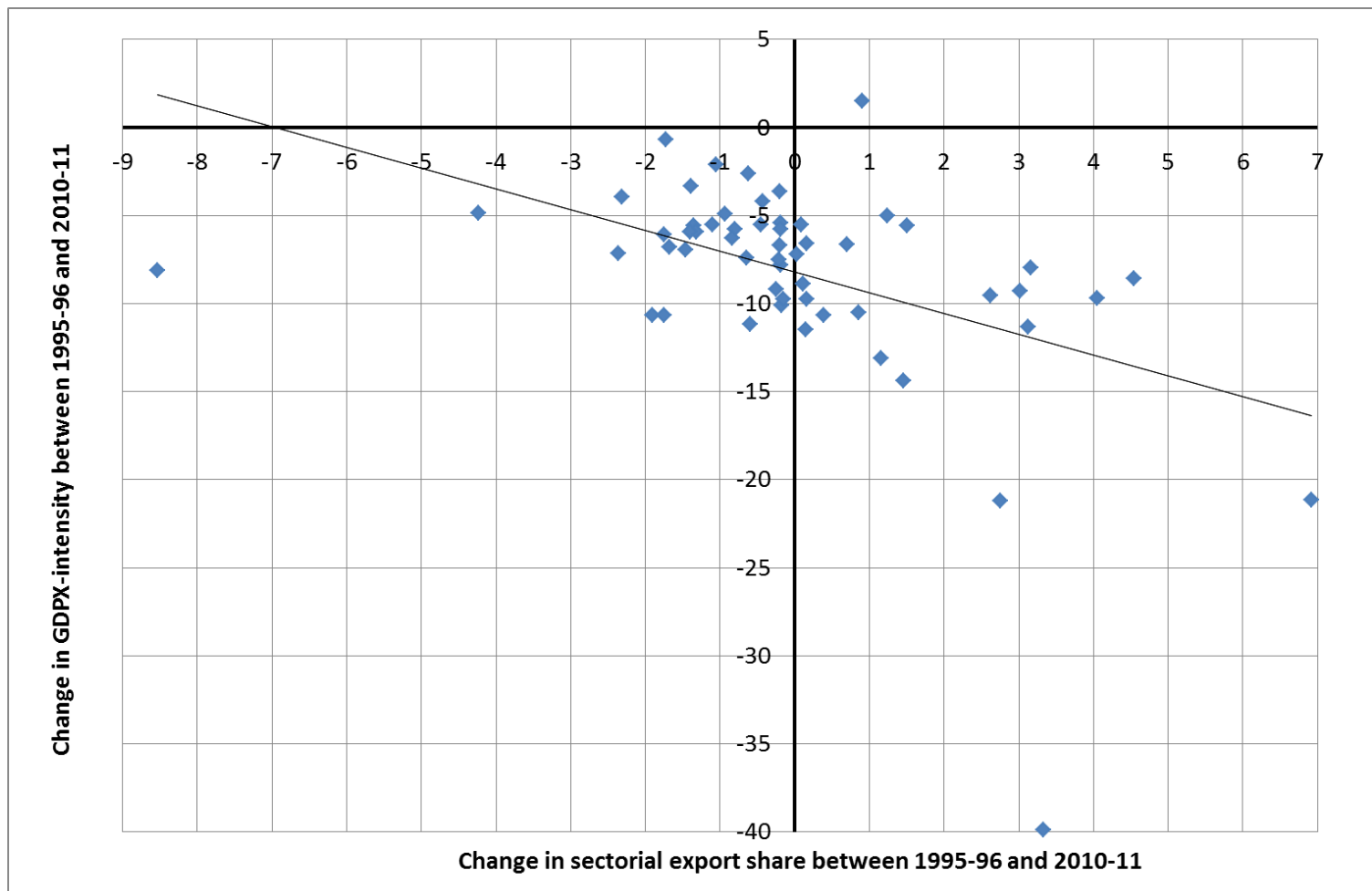

Source: authors' calculation on WIOD data.

(1) For each manufacturing sector in each country, the x-axis reports the variation between biennium 199596 and biennium 2010-11 in the sectoral export share (i.e., the share of that sector in the country's overall manufacturing exports); the y-axis reports the variation of the sectoral GDPX-intensity. The countries under examination are France, Germany, Italy and Spain. The OLS regression line is also reported.

\section{Concluding remarks}

We have offered an analysis of two competing metrics, market shares in manufacturing gross exports and market shares in value added (embodied in manufacturing exports), both in levels and in dynamics. We have focussed on the four largest economies of the euro-area within a broader context considering all forty countries available in our dataset and the dichotomy between advanced and developing economies. Our focus on France, Italy, Germany and Spain has widened the analysis by deepening into the sectoral dimension.

Moving from one metric to the other does not alter the "general picture", more so in levels than in dynamics, and more so for advanced large exporters than for emerging economies. Differences do arise, however, which can be non-negligible for individual countries and/or specific periods. Relative comparisons between countries are especially prone to be affected when such differences have opposite sign or diverge in time.

When considering all forty countries in the WIOD database, we find evidence supporting the common narrative interpretation of recent developments in GVCs: as emerging economies initially specialized in low-value-added manufacture and assembly activities, the large increase in their export shares was not matched by an equal surge in the domestic value added generated by exports; later on (we find 2004 to be the turning point), as these countries started climbing the "smile curve" towards pre- and post-manufacturing high-value-added services activities, the growth of emerging economies as surmised from market shares was stronger in value-added than in gross-exports terms.

When focusing on the largest euro-area countries, differences emerge in particular when we compare them one against the other: the performance of Germany is less outstanding when looked 
at in value-added terms, since the German share in value added contracted more than the corresponding share in gross exports throughout the period, while the opposite held for Italy and France.

Hence, there may be a trade-off between relatively more favourable market shares dynamics and the ability of gross exports in contributing to GDP growth. The findings of our sectoral analysis point in the same direction: on average, when a sector increases its share in a country's gross exports by 1 percentage point, its GDPX-intensity falls by almost 1.2 percentage points.

In conclusion, whereas in general evaluating a country's ability to compete on world markets by means of its GX-share is on average largely equivalent to grounding the evaluation on its GDPXshare, for specific time spans and/or countries the two metrics point to divergent indications. In fact, every year, on average, four out of forty countries record changes in their GX share and in their GDPX share with opposite sign. Even more strikingly, every year, on average, 5.4 per cent of the countries that experienced an increase in the level of gross exports actually recorded a decrease in the level of GDPX. That is, the quest for export expansion led to a GDP contraction, and the point is more subtle than the ordinary notion that only net exports matter for GDP growth. ${ }^{19}$

One the basis of these findings, we argue that international fragmentation of production weakens the causal link between "external competitiveness" developments and GDP growth. This is a warning about the perils of attributing excessive emphasis on export market shares developments when assessing "external competitiveness" as a synonym for "growth prerequisite" and calls for a more informed analysis of the underlying phenomena. Taking GDPX-shares into the picture indeed helps in this respect, despite this requires data that are not as timely and that involve considerable margins of uncertainty due to estimation.

\footnotetext{
${ }^{19}$ Net exports are also affected by the autonomous effect of internal demand on imports.
} 


\section{References}

Ahmad et al., "Using Trade Microdata to Improve Trade in Value-Added Measures, Proof of Concept Using Turkish Data", OECD Working Paper, no. 16, 2011.

Baldwin, R., " Global Supply Chains: Why They Emerged, Why They Matter, and Where They Are Going", Centre for Trade and Economic Integration Working Papers, The Graduate Institute, Geneva, 2012.

Benkovskis K. and J. Wörz, "Made in China - How Does it Affect our Understanding of Global Market Shares?”, ECB Working paper, no. 1787, 2015.

Bernard A. B. et al., "Firms in International Trade", Journal of Economic Perspectives, Summer 2007, 105-130.

Cappariello, R. and A. Felettigh, "How Does Foreign Demand Activate Domestic Value Added? A Comparison Among the Largest Euro-area Economies", Banca d'Italia working papers (Temi di discussione), no. 1001, February 2015.

Chen X. et al., "Domestic Value Added and Employment Generated by Chinese Exports: a Quantitative Estimation", China Economic Review, n. 23, 2012.

Dean J., K.C. Fung and Z. Wang, "Measuring Vertical Specialization: the Case of China", Review of International Economics, n. 19(4), 2011.

Feenstra, R. C. et al., "Report on the State of Available Data for the Study of International Trade and Foreign Direct Investment", NBER Working Paper series, no. 16254, 2010.

Feenstra, R. C. and J. B. Jensen, "Evaluating Estimates of Materials Offshoring from US Manufacturing", Economics Letters, no. 117, 2012.

Hummels, D., J. Ishii, and K. Yi, "The Nature and Growth of Vertical Specialization in World Trade", Journal of International Economics, no. 54, 2001.

Johnson, R., and G. Noguera. 2012. "Accounting for Intermediates: Production Sharing and Trade in Value-added", Journal of International Economics, 86(2012): 224-236.

Koopman R., Z. Wang. and S. Wei, "Tracing Value Added and Double Counting in Gross Exports", American Economic Review, 2014.

Krugman, P. R., “Competitiveness: A Dangerous Obsession”, Foreign Affairs 73 (2): 28-44, 1994.

Krugman, P. R., "Making Sense of the Competitiveness Debate", Oxford Review of Economic Policy 12 (3): 17-25, 1996.

Piacentini, M, 2015, "Firms Heterogeneity and Trade in Value Added", paper presented at the March 2015 meeting of the OECD Working Party on International Trade in Goods and Trade in Services Statistics.

Timmer, Marcel (ed.). 2012. "The World Input-Output Database (WIOD): Contents, Sources and Methods", WIOD background document available at http://www.wiod.org/. 


\section{Statistical Appendix}

Fig. A1. Market shares in gross exports and in value added, averages in biennium 1995-96 (1) (percentage points)

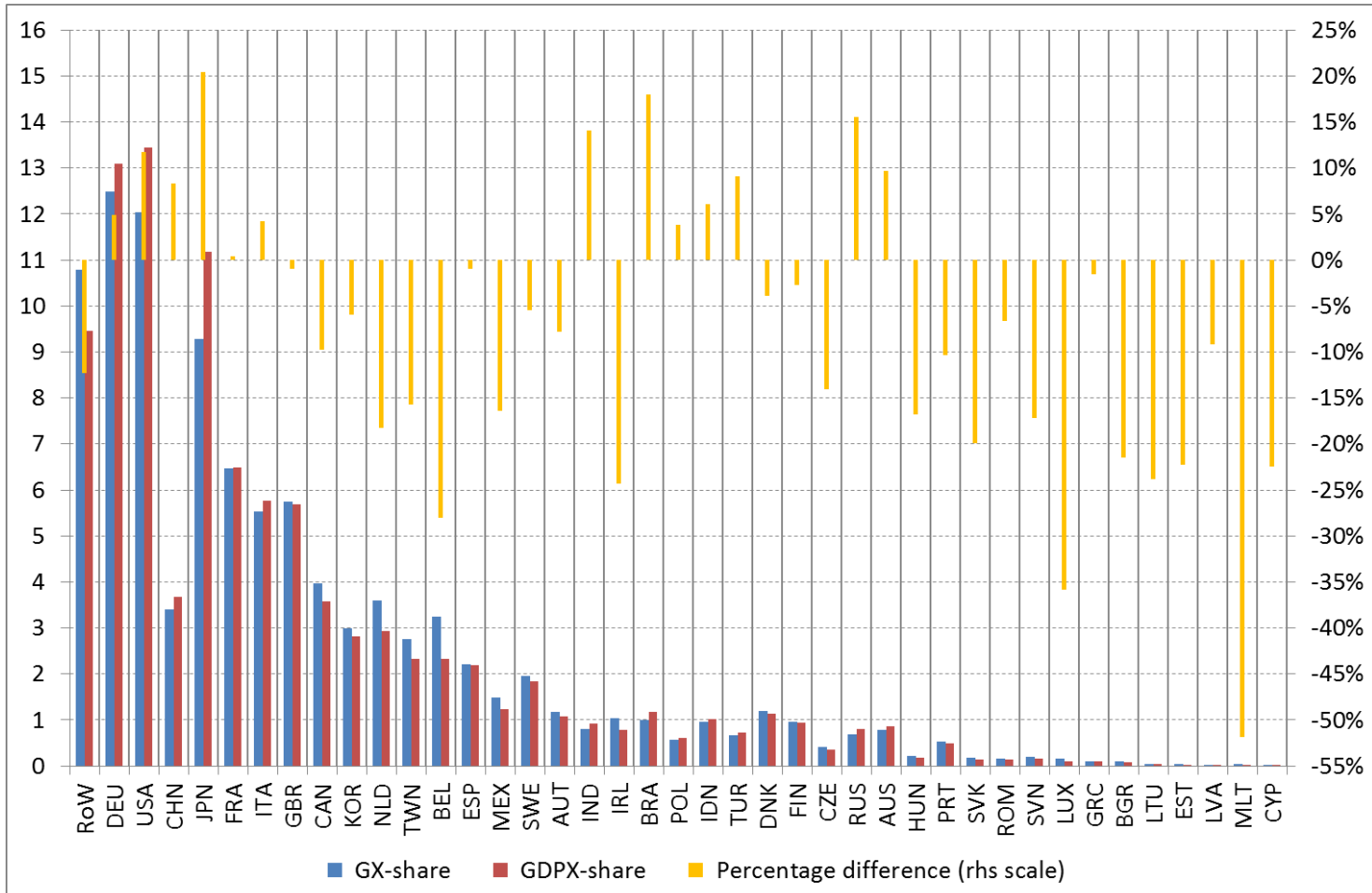

Source: authors' calculations on WIOD data.

(1) Countries are ordered as in Figure 1 in the main text. The percentage difference (right-hand scale) is computed between countries' GDPX-share and GX-share. Only exports of manufactures are considered.

Fig. A2. Market shares in gross exports and in value added, averages in biennium 2010-11 (1)

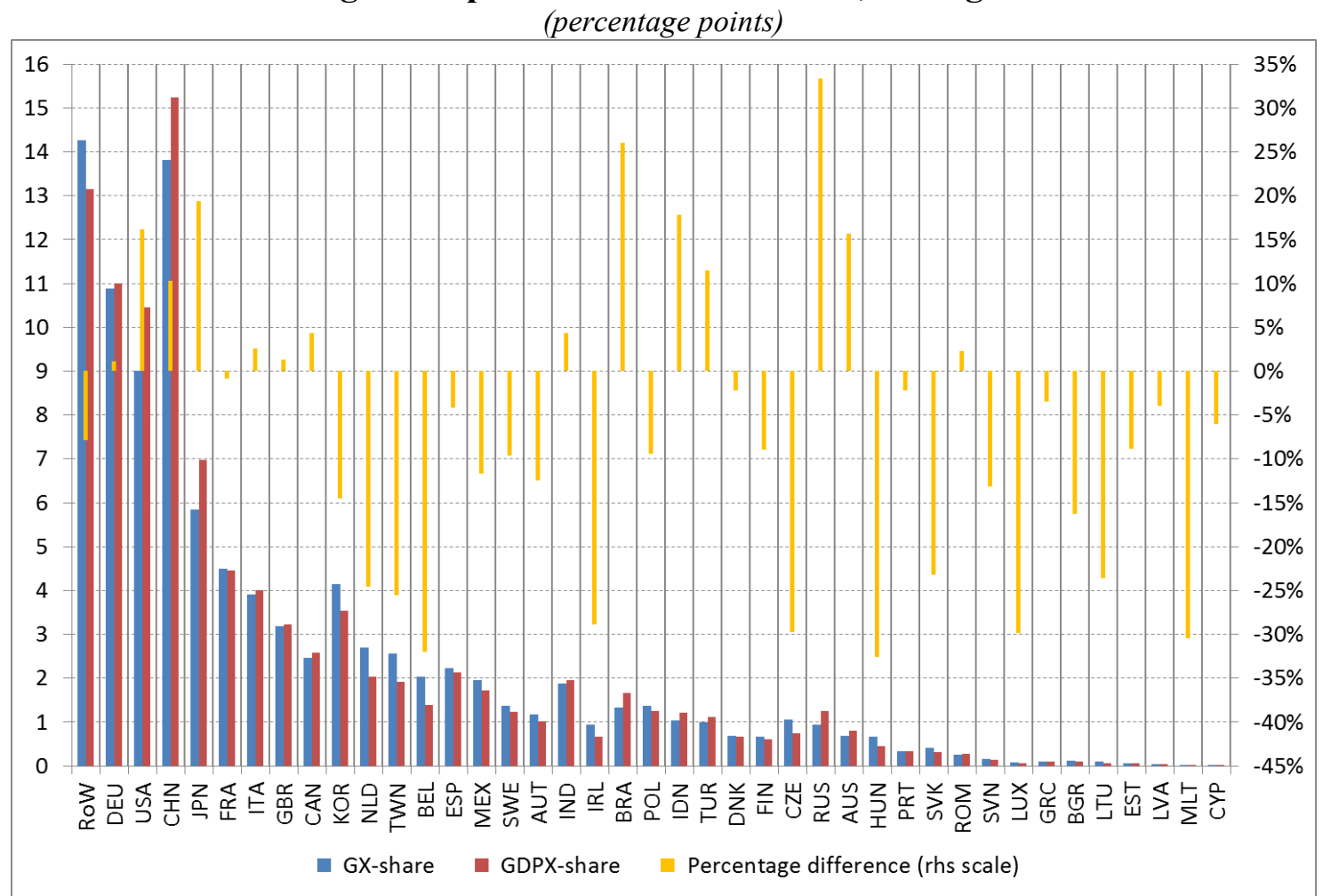

Source: authors' calculations on WIOD data.

(1) Countries are ordered as in Figure 1 in the main text. The percentage difference (right-hand scale) is computed between countries' GDPX-share and GX-share. Only exports of manufactures are considered. 
Figure A3. Gross exports and GDPX-intensity by country (1) (USD billion for exports; percentage points for GDPX-intensities, on the right-hand scale)

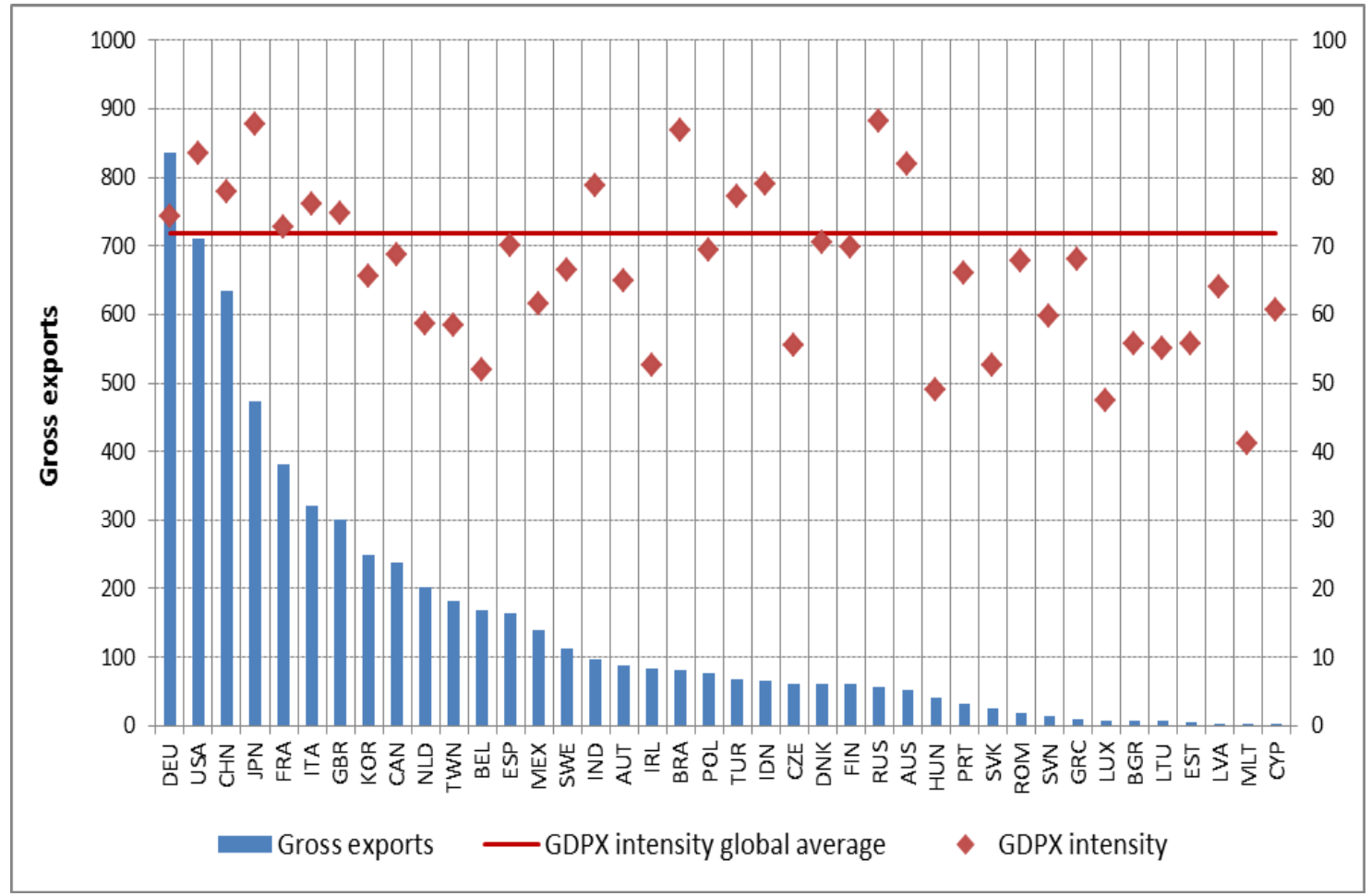

Source: Authors' calculation on WIOD data.

(1) All values are averaged over the whole period 1995-2011. Countries are ordered by size of gross exports. Only exports of manufactures are considered. GDPX-intensities are plotted on the right-hand scale.

Table A1. Sectoral GDPX-intensity variations between biennia 1995-96 and 2010-11 for the four largest euro-area countries

\begin{tabular}{lrrrr}
\multicolumn{5}{c}{ (percentage points) } \\
\hline & Italy & France & Germany & Spain \\
\hline Food, beverages and tobacco & -5.57 & -4.89 & -10.49 & -5.03 \\
Textiles & -4.84 & -0.66 & -6.10 & -6.63 \\
Leather and footwear & -3.35 & -3.65 & -6.68 & -5.92 \\
Wood and cork (and related products) & -5.40 & -7.52 & -11.47 & -5.76 \\
Pulp, paper, printing and publishing & -4.19 & -2.09 & -7.79 & -2.65 \\
Coke, refined petroleum and nuclear fuel & -39.88 & -21.20 & 1.51 & -21.18 \\
Chemical and pharmaceutical products & -9.27 & -7.98 & -10.11 & -8.60 \\
Rubber and plastics & -7.19 & -9.73 & -10.67 & -5.52 \\
Other non-metallic mineral products & -6.82 & -5.80 & -9.17 & -6.97 \\
Basic metals and fabricated metal & -9.68 & -7.43 & -14.37 & -9.52 \\
Machinery & -5.58 & -5.53 & -10.69 & -5.93 \\
Electrical, IT and optical equipment & -5.51 & -7.13 & -11.18 & -10.68 \\
Transport equipment & -8.86 & -11.34 & -13.11 & -8.10 \\
Manufacturing n.e.c. and recycling & -3.96 & -6.61 & -9.77 & -6.31 \\
Total manufacturing & $\mathbf{- 9 . 7 6}$ & $\mathbf{- 9 . 2 1}$ & $\mathbf{- 1 1 . 3 0}$ & $\mathbf{- 1 0 . 4 6}$ \\
\hline Sourc: & & & &
\end{tabular}

Source: authors' calculations on WIOD data. 


\section{Methodological Appendix}

WIOD tables, as the vast majority of available IO tables, assume that all producers within a sector are homogeneous ("homogeneity assumption"). On the contrary, it is a fact that different productions within a sector (or even within a firm) are characterized by a different intensity of domestic value added. Even if we take as correct the WIOD estimate for the overall value added generated by a sector in a given country, ${ }^{20}$ the domestic-value added content of its exports (the "true" GDPX-intensity of that sector) then also depends on how each production is split between domestic consumption and exports.

Measuring accurately the GDPX-intensity of a sector requires distinguishing all its "productions" on the basis of both their own GDPX-intensity and their propensity to be exported (i.e. what share of total production is sold abroad) ${ }^{21}$ Among the factors affecting this characteristics pair, the following are of crucial importance, and they ought to be taken into account (to the maximum possible extent) when compiling official statistics:

- Exporting status. Exporters are more likely to be also importers, and this tends to be reflected in a lower GDPX-intensity; on the other side, non-exporters do not contribute to GDPX at all. Also, especially in developing countries, goods for exports tend to be of a higher "quality", which may entail a larger resort to imported intermediate inputs. More generally, there is a wide consensus in the literature that exporters are "special", in developing and developed countries alike, in that they are bigger, more productive, pay higher wages and so on (see the classic survey in Bernard et al., 2007).

- "Processing trade", 22 that is exports of goods processed in the country using imports of intermediates from abroad, imported under the strict condition of being used only in the exportoriented production (an extreme case of exporting status). Specifically targeted policies are often in place in order to favour processing trade: imports of intermediate goods are usually waived by tariffs and receive special customs treatment under the condition that they are not used in the production for the local market.

- Foreign ownership or being part of a multi-national group. Firms that are foreign-owned or that belong to a multi-national group are more likely to be interconnected in GVCs, so that they tend to import more intermediate inputs, which is reflected in a lower GDPX-intensity.

The "homogeneity assumption" we have been discussing is related to the well-known "proportionality assumption" 23 nested in input-output tables, as the former refers to the computation of domestic value added in exports, while the latter is related to imports of intermediate inputs. National input-output tables do not have information on the allocation of imported intermediates across domestic sectors. This is estimated using the "proportionality assumption": in each sector and for each intermediate input, the share of imported intermediates in total demand for that input by that sector is computed as the corresponding share for the entire economy. ${ }^{24}$ This is equivalent to

\footnotetext{
${ }^{20}$ That is, we take as granted that WIOD tables measure each country's GDP correctly.

${ }^{21}$ The main obstacle to fulfilling this goal is, at present, data availability, although efforts are under way to disentangle trade on the basis of enterprise characteristics (Trade by Enterprise Characteristics, in the OECD wording), and some preliminary estimations for a restricted set of countries are available: see for instance Piacentini (2015).

${ }^{22}$ The World Custom Organisation defines "processing trade" as «the Customs procedure under which certain goods can be brought into a custom territory conditionally relieved from payment of tariffs and taxes on the basis that such goods are intended for manufacturing, processing or repair and subsequent exportation».

${ }^{23}$ Also named "import comparability" assumption; see for example Feenstra et al. (2010), and Feenstra and Jensen (2012).

${ }^{24}$ WIOD supply and use tables improve upon the standard "proportionality assumption" by resorting to bilateral trade data on import flows disaggregated according to the Broad Economic Categories (BEC) classification, which assigns each good to a use category (intermediates, final consumption or investment) depending on its prevalent use. The proportionality assumption is then applied within the use category of intermediates.
} 
posing that imported inputs are used evenly across sectors and, within sectors, in the production of domestic and exports sales.

In summary, GDPX may be over-estimated when calculated using ordinary IO tables, i.e. under the homogeneity assumption. The bias might be particularly large for the emerging countries more involved in processing trade, as in this case two distinct "production regimes" are likely: one devoted mainly to sales abroad and the other one to internal consumption. How large can this measurement bias be? In order to have a sense of the answer, we substituted for China and Mexico the GDPX-intensities we derived from the WIOD dataset with the improved estimates taken from Koopman, Wang and Wei (2014), as mentioned in the main text. ${ }^{25}$ We then recalculated the shares in global value added of all the countries in WIOD for the benchmark year 2005. The results are shown in Table A2; total domestic value added embodied in world exports shrinks by a mere 1.2\%; at the country level, the GDPX-shares of China and Mexico are heavily reduced, with no significant change, however, for the other main exporters in the world.

Table A2. Potential bias in measurement of domestic value added in 2005 (1)

(USD million for exports and GDPX; percentage points for GDPX-intensities and shares)

\begin{tabular}{lccccrrr}
\hline Country & $\begin{array}{c}\boldsymbol{\gamma} \\
\text { (origin } \\
\text { al } \\
\text { value) }\end{array}$ & $\begin{array}{c}\boldsymbol{\gamma} \\
\text { (revised } \\
\text { value)* }\end{array}$ & $\begin{array}{c}\text { Gross } \\
\text { exports }\end{array}$ & $\begin{array}{c}\text { GDPX } \\
\text { (original } \\
\text { value) }\end{array}$ & $\begin{array}{c}\text { GDPX } \\
\text { (revised } \\
\text { value) }\end{array}$ & $\begin{array}{c}\boldsymbol{\sigma} \\
\text { (original } \\
\text { value) }\end{array}$ & $\begin{array}{c}\boldsymbol{\sigma} \\
\text { (revised } \\
\text { value) }\end{array}$ \\
\hline China & 70.7 & 63.6 & 682343 & 482299 & 433970 & 8.9 & 8.1 \\
Germany & 72.4 & & 946499 & 685251 & 685251 & 12.6 & 12.8 \\
Spain & 68.8 & & 183011 & 125908 & 125908 & 2.3 & 2.3 \\
France & 71.7 & & 418714 & 300134 & 300134 & 5.5 & 5.6 \\
Italy & 75.1 & & 351033 & 263674 & 263674 & 4.9 & 4.9 \\
Japan & 86.9 & & 516887 & 448929 & 448929 & 8.3 & 8.4 \\
Mexico & 59.5 & 51.7 & 151079 & 89871 & 78108 & 1.7 & 1.5 \\
US & 81.8 & & 722755 & 591298 & 591298 & 10.9 & 11.0 \\
\hline World & 69.2 & & 7850625 & 5434379 & 5374287 & 100.0 & 100.0 \\
\hline
\end{tabular}

Source: authors' calculations on WIOD data and estimates from Koopman, Wang and Wei (2014).

(1) In the notation introduced earlier, $\gamma$ denotes the GDPX-intensity, $\sigma$ denotes the market share in world GDPX. Only exports of manufactures are considered.

(*) Data for China and Mexico are taken from Koopman, Wang and Wei (2014).

The exercise is rather simplistic, since a thorough assessment of the impact of the homogeneity bias would require correcting estimates for all the countries in the dataset (including advanced economies). Moreover, revised values of the GDPX-intensity $\gamma$ as taken from KWW (2014) are calculated on export flows of goods and services; since exports of services tend to be much more GDPX-intensive than exports of goods, it is very likely that a revised estimate of $\gamma$ for manufacturing exports alone would lead to an even lower value than that reported by KWW. We can conclude from our tentative assessment that shares in value added seem to be sufficiently robust to reasonable revisions to country-level GDPX-intensities, even if we would expect some rebalancing in favour of advanced countries to occur if the homogeneity bias were properly dealt with in corrected and improved global IO tables.

\footnotetext{
${ }^{25}$ The GDPX-intensity for China calculated by the three authors is very close to the value published by the OECD in the TiVA database, where data for China were corrected from 2005 onwards thanks to the availability of more disaggregated IO tables.
} 